\title{
Natural Products
}

\section{${ }_{Y}$ Ciscoveries and Challenges en Route to Swinhoeisterol A}

\author{
Fenja L. Duecker, ${ }^{[a]}$ Robert C. Heinze, ${ }^{[a]}$ Simon Steinhauer, ${ }^{[b]}$ and Philipp Heretsch ${ }^{*[a]}$
}

Abstract: In this work, a full account of the authors' synthetic studies is reported that culminated in the first synthesis of $13(14 \rightarrow 8), 14(8 \rightarrow 7)$ diabeo-steroid swinhoeisterol $A$ as well as the related dankasterones $A$ and $B, 13(14 \rightarrow 8)$ abeo-steroids, and periconiastone $A$, a $13(14 \rightarrow 8)$ abeo-4,14-cyclo-steroid. Experiments are described in detail that provided further in- sight into the mechanism of the switchable radical framework reconstruction approach. By discussing failed strategies and tactics towards swinhoeisterol $A$, the successful route that also allowed an access to structurally closely related analogues, such as $\Delta^{22}$-24-epi-swinhoeisterol $A$, is eventually presented.

\section{Introduction}

Traditionally, the majority of bioactive compounds has been isolated from terrestrial plants and fungi, whereas the marine biosphere was more difficult to access. Undersea organisms often produce structurally highly complex, rearranged secondary metabolites with unique bioactivities. ${ }^{[1]}$

An increasing number of chemical syntheses relies on biogenetic information, gaining access to natural products via biomimetic approaches. ${ }^{[2]}$ Still, many of the proposed pathways are established without the support of co-isolated biosynthetic precursors from the producing organism. Commonly, biogenetic proposals anticipate polar pathways to account for skeletal rearrangements and radical routes are rarely considered. ${ }^{[3]}$ One class of steroidal natural products with such rearranged skeletons are the so-called abeo-steroids, which display one or several $\mathrm{C}-\mathrm{C}$ bond migrations with respect to the classic, tetracyclic steroid backbone. ${ }^{[4]}$

In recent years, our group as well as others have demonstrated that key synthetic transformations (possibly biomimetic in nature) can indeed be carried out using radical reactivity,

[a] F. L. Duecker, Dr. R. C. Heinze, Prof. Dr. P. Heretsch Institut für Chemie und Biochemie, Organische Chemie Freie Universität Berlin

Takustrasse 3, 14195 Berlin (Germany)

E-mail:philipp.heretsch@fu-berlin.de

[b] Dr. S. Steinhauer

Institut für Chemie und Biochemie, Anorganische Chemie

Freie Universität Berlin

Fabeckstrasse 34-36, 14195 Berlin (Germany)

$\square$ Supporting information and the ORCID identification number(s) for the au-

iD thor(s) of this article can be found under: https://doi.org/10.1002/chem.202001405.

of (c) 2020 The Authors. Published by Wiley-VCH Verlag GmbH \& Co. KGaA This is an open access article under the terms of Creative Commons Attribution NonCommercial-NoDerivs License, which permits use and distribution in any medium, provided the original work is properly cited, the use is non-commercial and no modifications or adaptations are made.

$\overline{\mathbf{Y}}$ C Part of a Special Collection to commemorate young and emerging scientists. To view the complete issue, visit: Young Chemists 2020. giving the desired skeletal modifications with high selectivity as shown in the syntheses of rearranged steroids cortistatin $A_{1}^{[5]}$ aplysiasecosterol $A_{1}^{[6]}$ strophasterol $A_{1}^{[7]}$ pleurocin $A /$ matsutakone ${ }^{[8]}$ and herbarulide ${ }^{\left[{ }^{[9]}\right.}$ It was also a cascade of rearrangements initiated by an alkoxy radical that cleared the way to the dankasterone $[13(14 \rightarrow 8) \text { abeo-steroids }]^{[10]}$ and the swinhoeisterol class of natural products $[13(14 \rightarrow 8), 14(8 \rightarrow 7)$ diabeosteroids]. ${ }^{[1]]}$ Only recently, we achieved the synthesis of swinhoeisterol A (2), its 24-epi-counterpart (24-epi-2), dankasterone $A(3)$ and $B(4)$, and periconiastone $A(5),{ }^{[12]}$ the 4,14-cyclo aldol product of the latter, starting from commercial ergosterol (1) by exploiting a radical cascade (Scheme 1). ${ }^{[13]}$ Regarding the biological activities of these natural products, dankasterone $A$ (3) and B (4) show significant cytotoxicity against the P388 lymphocytic leukemia test system $\left(E_{50} 2.2\right.$ and $2.8 \mu \mathrm{g} \mathrm{mL}^{-1}$, respectively ${ }^{[10]}$ whereas diabeo-steroid swinhoeisterol A (2) exhibits a remarkable inhibition of the histone acetyltransferase (h)p300 with an $I C_{50}$ of $2.9 \mu \mathrm{M}$. ${ }^{[11 a]}$ The most recently isolated
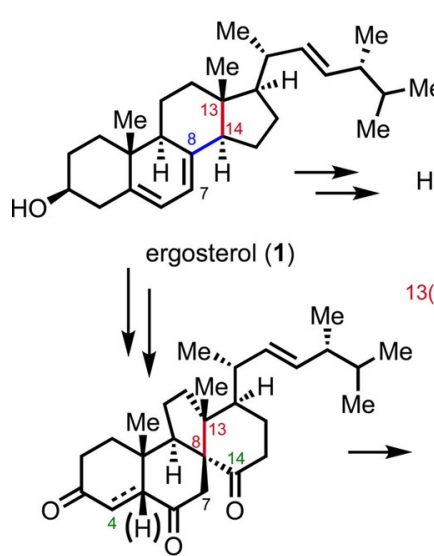

dankasterone $\mathrm{A}\left(3, \Delta^{4}\right) ; \mathrm{B}(4,5 \beta-\mathrm{H})$

$13(14 \rightarrow 8)$ abeo-ergostane

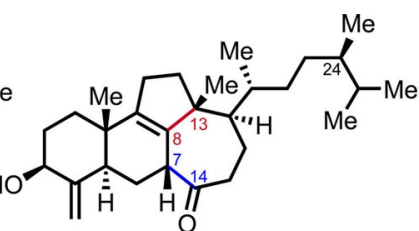

swinhoeisterol A (2)

$13(14 \rightarrow 8), 14(8 \rightarrow 7)$ diabeo-4a-homocampestane

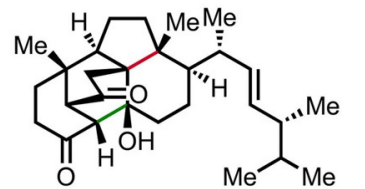

periconiastone $\mathrm{A}(\mathbf{5})$

$13(14 \rightarrow 8)$ abeo-4,14-cyclo-ergostane
Scheme 1. Structures of the abeo-steroids swinhoeisterol A (2), dankasterone $A(3)$ and $B(4)$, and periconiastone $A(5)$, their common synthetic starting material, ergosterol (1), as well as their generic classes. 
secondary metabolite, periconiastone A (5), is reported to display intriguing antibacterial activity against two Gram-positive microbial pathogens, namely S. aureus (MIC $4 \mu \mathrm{g} \mathrm{mL}^{-1}$ ) and $E$. faecalis (MIC $32 \mu \mathrm{g} \mathrm{mL}^{-1}$ ). ${ }^{[12]}$

Herein, we want to report on the evolution of our synthetic studies towards swinhoeisterol A (2) and its 24-epi-isomer (24epi-2) as well as present experimental support for our mechanistic proposal for our radical framework reconstruction approach.

\section{Results and Discussion}

Our rationale to gain synthetic access to the rearranged skeletons of abeo-steroids relied on the initial generation of an alkoxy radical. The following radical rearrangement (Scheme 2) enabled the synthesis of the above-mentioned natural products and selective access to either the mono- or diabeo-skeleton was gained by adapting the reaction conditions $\left(\mathrm{Phl}(\mathrm{OAC})_{2} / \mathrm{I}_{2}\right.$ for the former; $\mathrm{HgO} / \mathrm{I}_{2}$ for the latter) to generate $B$, starting from a $\gamma$-hydroxy enone $A$. Subsequent $\beta$ scission of the C13-C14 bond in B would form an intermediary 14-oxo functionality along with a stabilized tertiary radical at C13 (C). An attack onto the $\Delta^{7}$-bond generates $\alpha$-keto radical $D$, which is either quenched reductively to give the $13(14 \rightarrow 8)$ abeo skeleton $(E)^{[14]}$ as present in the dankasterone class of natural products, or further reacts in a Dowd-Beckwith rearrangement. ${ }^{[15]}$ This comprises of an attack of the C7-centered radical to the 14-oxo functionality to give alkoxy radical F. Another $\beta$ scission, this time of $\mathrm{C} 8-\mathrm{C} 14$, yields the $13(14 \rightarrow 8), 14(8 \rightarrow 7)$ diabeo core (G) of the swinhoeisterols after abstraction of an $\mathrm{H}$ atom ( $\mathrm{G} \rightarrow$ $\mathrm{H})$.

Initially, $5 \alpha$-hydroxy enone $\mathbf{7}$ was chosen as a substrate for the envisioned radical rearrangement (Scheme 3). As we described in our synthesis of herbarulide, ${ }^{[9]}$ the preparation of Burawoy's ketone (6) following reported procedures has proven to lack reproducibility. ${ }^{[16]}$ Aiming for a stepwise oxida-

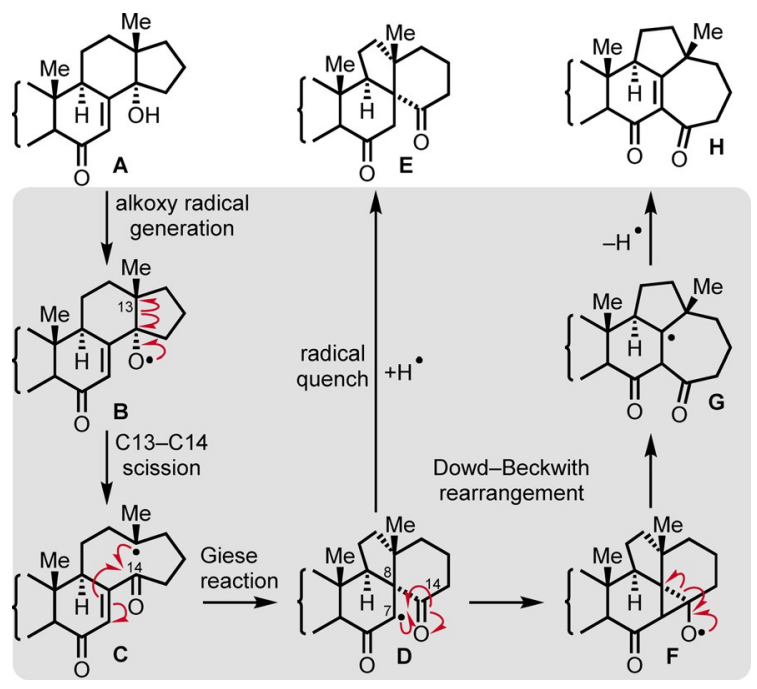

Scheme 2. Mechanistic proposal for the alkoxy radical initiated framework reconstruction leading to the structural precursors of the dankasterones $\mathbf{E}$ and swinhoeisterols $\mathbf{H}$.
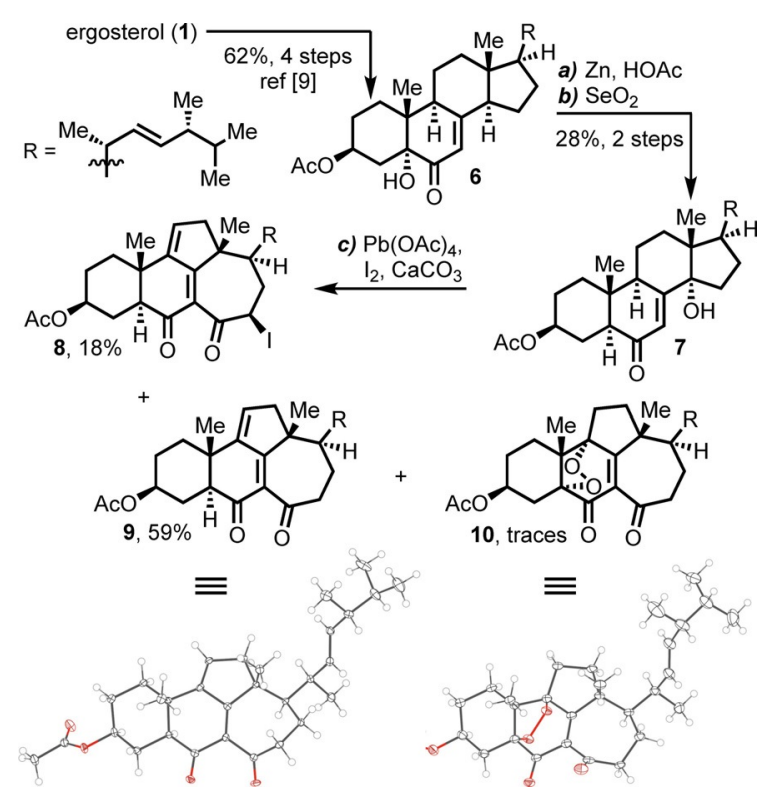

Scheme 3. Radical rearrangement of 7 leading to the $13(14 \rightarrow 8), 14(8 \rightarrow$ 7)diabeo structures 8,9 , and 10. ORTEP plots of 9 and 10 . Thermal ellipsoids are drawn at $50 \%$ probability. Reagents and conditions: a) Zn (29 equiv.), $\mathrm{HOAc}, 90^{\circ} \mathrm{C}, 3 \mathrm{~h}, 47 \%$; b) $\mathrm{SeO}_{2}$ (4.75 equiv.), $\mathrm{tBuOH} /$ pyridine $(4: 1), 80^{\circ} \mathrm{C}, 4 \mathrm{~h}$, $59 \%$; c) $\mathrm{Pb}(\mathrm{OAc})_{4}$ (2.0 equiv.), $\mathrm{I}_{2}$ (2.0 equiv.), $\mathrm{CaCO}_{3}$ (2.0 equiv.), $\mathrm{C}_{6} \mathrm{H}_{6}, 85^{\circ} \mathrm{C}$, 2 h, 8: 18\%, 9: 59\%, 10: traces. CCDC 1991055 (9) and 1991054 (10) contain the supplementary crystallographic data (see Experimental Section).

tion of ergosterol (1), 6 was available in $62 \%$ yield over 4 steps. ${ }^{[9]}$ Reduction with zinc in acetic acid provided $5 \alpha$-enone (not shown) in $47 \%$ along with $20 \%$ of its $5 \beta$-epimer (not shown). While Riley oxidation employing 1,4-dioxane as solvent gave the desired product in only low and irreproducible yields, the solvent system pyridine/ $\mathrm{BuOH}^{[17]}$ allowed for the formation of alcohol 7 in an acceptable yield of $59 \%$. To generate the alkoxy radical at $\mathrm{C} 14$ from alcohol 7, the literature-known combination of $\mathrm{Pb}(\mathrm{OAc})_{4}, \mathrm{I}_{2}$ and $\mathrm{CaCO}_{3}$ in benzene ${ }^{[18]}$ was used and, indeed, all isolated products showed the desired $13(14 \rightarrow$ $8), 14(8 \rightarrow 7)$ diabeo-skeleton, though in higher oxidation states than expected. Diene dione 9 was obtained as the major product $(40 \%)$ along with endoperoxide 10 (20\%). When the reaction mixture was carefully degassed prior to addition of

Philipp Heretsch was born in Lippstadt, Germany, in 1982. He obtained his PhD degree from Universität Leipzig (supervisor: A. Giannis) in 2009. After a postdoctoral stay with K.C. Nicolaou at The Scripps Research Institute, La Jolla, California, and at Rice University, Houston, Texas, he was appointed assistant professor at Freie Universität Berlin in 2015. Philipp Heretsch has been working in the total synthesis of natural products since the beginning of his career. His group is now pursuing framework reconstruction strategies for the synthesis of abeo-steroids and alkaloids, guided by biosynthetic hypotheses.

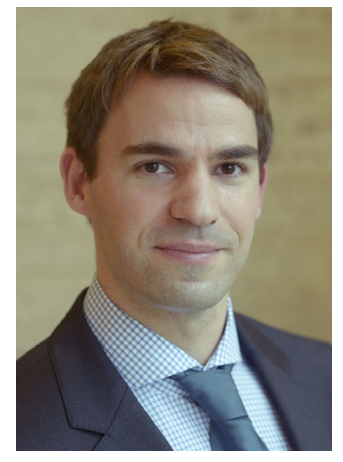


$\mathrm{Pb}(\mathrm{OAc})_{4}, 59 \%$ of 9 , only traces of 10 , and $18 \%$ of $15 \beta$-iodo diene dione $\mathbf{8}$ were obtained.

To prevent formation of the oxygen adduct and to keep options for later A-ring functionalization, elimination of the tertiary alcohol in Burawoy's ketone (6) was carried out using thionyl chloride and basic conditions to give $\Delta^{4}$-enone 11 (75\% yield). In this case, standard Riley conditions gave $\Delta^{4}$-hydroxy enone 12 as another substrate for the radical cascade. Again, the $\mathrm{Pb}(\mathrm{OAc})_{4} / \mathrm{I}_{2}$-system was used leading to a different product distribution for "open flask" and "degassed" conditions (see Scheme 4). Tetraene dione 13 was isolated as the major product $(31 \%$ yield) and its yield could be improved to $44 \%$ when carefully degassing the reaction mixture. Under "open flask" conditions, 4-iodo substituted endoperoxides 16 and 17 were obtained in 12 and $23 \%$ yield, respectively, or in 9 and $11 \%$ for the "degassed" experiment. The formation of 16 and 17 presumably results from remaining traces of oxygen in the reaction mixture. Interestingly, aerobic conditions led to the isolation of $15 \beta$-iodo tetraene dione $14(14 \%)$ whereas oxygen-free conditions delivered the $13(14 \rightarrow 8)$ abeo species $15(13 \%)$, instead, providing first confirmation of our mechanistic proposal (Scheme 2).

Gaining synthetic access to the swinhoeisterols by further processing one or several of the obtained products was tested on tetraene dione 13 (Scheme 5) as well as epimeric 4-iodo endoperoxides 16 and 17 (Scheme 6). For 13, we envisioned to reduce the oxo-functionality at $\mathrm{C} 6$ to the corresponding allylic alcohol, which could then be used to perform a sigmatropic rearrangement, either directly (Johnson-Claisen), after acetylation (Ireland-Claisen), or after methyl stannylation ([2,3]Wittig-Still), thereby installing a precursor for the exo-methylene function at C4. However, no conversion of starting material was observed when applying Johnson-Claisen conditions to the allylic alcohol and in case of the [2,3]-Wittig-Still rearrangement, addition of $n B$ BuLi to the methyl stannylated alcohol only resulted in the formation of the 1,2-rearranged product. In case of the Ireland-Claisen reaction, the allylic acetate was successfully converted to the corresponding silyl ketene acetal as judged by ${ }^{1} \mathrm{H}$ NMR, but further reaction to the desired carboxylic acid was not successful.

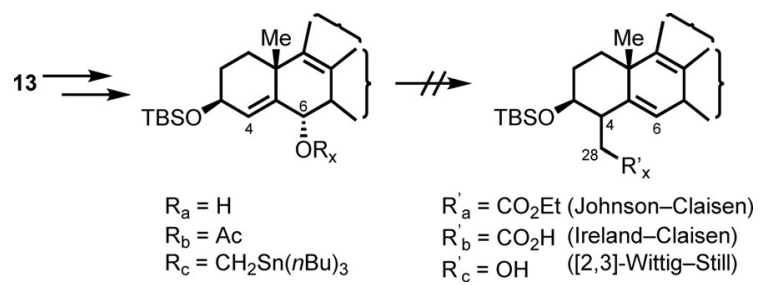

Scheme 5. Attempted sigmatropic rearrangements to introduce a synthetic precursor for the desired exo-methylene unit.
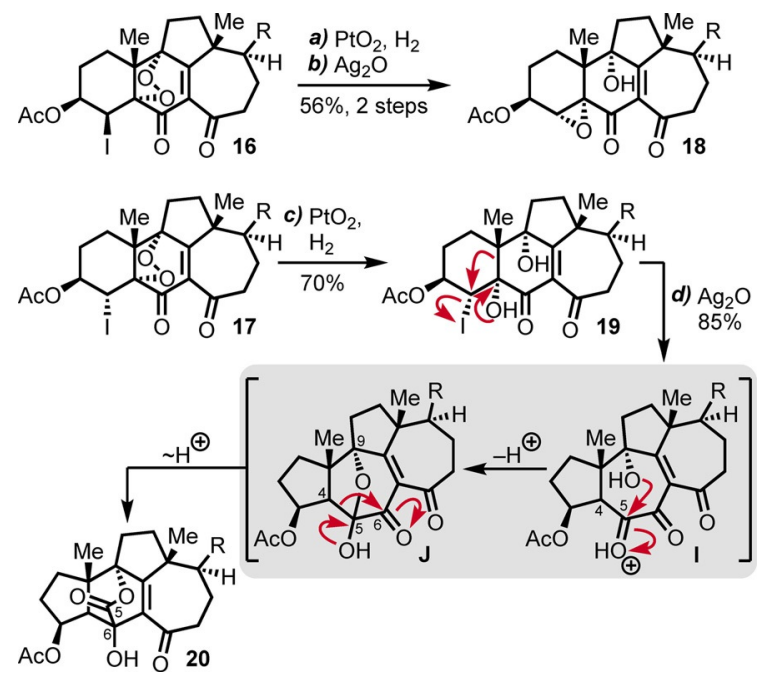

Scheme 6. Synthetic transformations of endoperoxides 16 and 17 and mechanistic proposal for the rearrangement to 20. Reagents and conditions: a) $\mathrm{PtO}_{2}$ (0.2 equiv.), $\mathrm{H}_{2}$ (balloon), EtOAc, $25^{\circ} \mathrm{C}, 4 \mathrm{~h}$; b) $\mathrm{Ag}_{2} \mathrm{O}, \mathrm{THF}, 25^{\circ} \mathrm{C}, 1 \mathrm{~h}$, $56 \%$ (2 steps); c) $\mathrm{PtO}_{2}$ (0.2 equiv.), $\mathrm{H}_{2}$ (balloon), EtOAc, $25^{\circ} \mathrm{C}, 4 \mathrm{~h}, 70 \%$; d) $\mathrm{Ag}_{2} \mathrm{O}, \mathrm{THF}, 60^{\circ} \mathrm{C}, 16 \mathrm{~h}, 85 \%, \mathrm{R}$ as in Scheme 3.

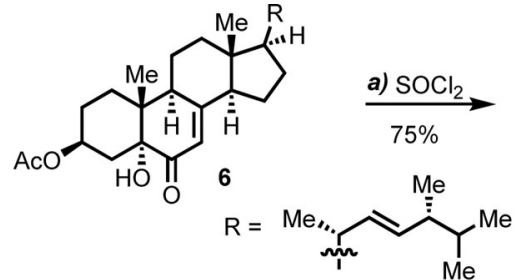

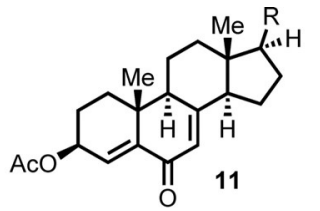<smiles>CO[AsH3]</smiles><smiles>[R2]C1=CC(=O)C2=CC(OC(C)=O)CCC2(C)C12CCC1(C)C([R])CCC12O</smiles>
c) $\mathrm{Pb}(\mathrm{OAc})_{4}$ $\mathrm{I}_{2}, \mathrm{CaCO}_{3}$

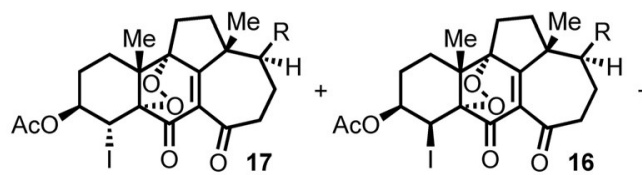

(see Scheme 6)

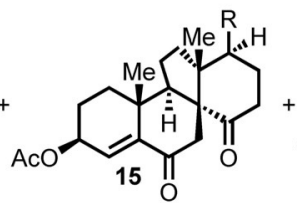
(see Scheme 7)

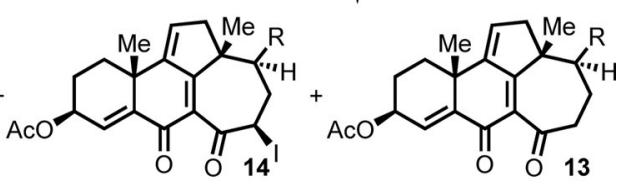

(see Scheme 5)

\begin{tabular}{|c|c|c|c|c|c|}
\hline "open flask" & $23 \%$ & $12 \%$ & - & $14 \%$ & $31 \%$ \\
\hline "degassed" & $11 \%$ & $9 \%$ & $13 \%$ & - & $44 \%$ \\
\hline
\end{tabular}

Scheme 4. Radical rearrangement of 12 and product distributions depending on the reaction conditions. Reagents and conditions: a) SOCl $\mathrm{I}_{2}(4.5$ equiv.), pyridine, $-10^{\circ} \mathrm{C}, 45 \mathrm{~min}, 75 \%$; b) $\mathrm{SeO}_{2}$ (4.75 equiv.), dioxane $\left./ \mathrm{H}_{2} \mathrm{O}(50: 1), 65^{\circ} \mathrm{C}, 5 \mathrm{~h}, 73 \% ; \mathrm{c}\right) \mathrm{Pb}(\mathrm{OAc})_{4}\left(2.0\right.$ equiv.), $\mathrm{I}_{2}\left(1.5\right.$ equiv.), $\mathrm{CaCO}_{3}\left(2.0\right.$ equiv.), $\mathrm{C}_{6} \mathrm{H}_{6}, 85^{\circ} \mathrm{C}, 2 \mathrm{~h}$, $\mathrm{R}$ as in Scheme 3. 
Since the diastereomeric endoperoxides 16 and 17 contained the structural motif of a $\Delta^{7}-9 \alpha$-hydroxy ketone, which is also present in other members of the swinhoeisterols, they were also assumed valuable intermediates en route to 2 (Scheme 6). Thus, reduction of the peroxide functionality to the corresponding 5,9-diol (as in 19) was carried out on both 4-iodo epimers using $\mathrm{PtO}_{2} / \mathrm{H}_{2}$. In case of $4 \beta$-iodo endoperoxide 16, a mixture of the diol (not shown) and epoxide 18 resulting from concomitant $\mathrm{S}_{\mathrm{N}} 2$ reaction was obtained. Full conversion was possible by treatment with $\mathrm{Ag}_{2} \mathrm{O}$ and gave 18 in $56 \%$ over 2 steps. As 18 was deemed a suitable precursor for further transformations (e.g., Wharton transposition), diol 19 was to be transformed to 18 as well through a $S_{N} 1$ reaction. Treatment with $\mathrm{Ag}_{2} \mathrm{O}$ showed no conversion at room temperature but after $16 \mathrm{~h}$ at $60^{\circ} \mathrm{C}$ selective formation of a new product was observed. Careful analysis of the NMR data obtained led us to propose the structure of lactone 20, which was confirmed by X-ray single crystal structure analysis. Presumably, formation of the expected cation at C4 did indeed take place but was immediately or concertedly followed by bond migration to give $10(5 \rightarrow 4)$ abeo intermediate I.

Assumedly, this oxocarbenium facilitated an attack of the C9 hydroxyl and thereby set the stage for a benzilic acid-type rearrangement ring contraction/expansion ${ }^{[19]}$ (see structure J) yielding lactone 20, which features immense connectivity changes in the $A$ and $B$ ring. To the best of our knowledge, this structural motif has not been observed in any steroidal context, before. Afore mentioned Wharton transposition was envisioned to convert epoxide 18 to C4 allylic alcohol, but as the initial conversion to the corresponding hydrazone was unsuccessful, further studies employing iodo-endoperoxides 16 and 17 were discarded.

Another compound isolated from the reaction of 12 with $\mathrm{Pb}(\mathrm{OAc})_{4} / \mathrm{I}_{2}$ was $\Delta^{4}-13(14 \rightarrow 8)$ abeo-steroid 15 . Although not further employed in the synthesis of the swinhoeisterols, its isolation supported our mechanistic proposal and transformation to dankasterone A (3) in $56 \%$ yield over two steps (Scheme 7) was successful. In the meantime, we were able to provide proof of the cage-like $13(14 \rightarrow 8)$ abeo-4,14-cyclo structure of periconiastone $A(5)^{[12]}$ by $X$-ray single crystal analysis. Previously, we had synthesized 5 from dankasterone $B(4)^{[13]}$ and now set out to explore the possibility to generate an enolate by 1,4-reduction of dankasterone A (3), which would then undergo aldol addition and give the desired 4,14-cyclo skeleton. Interestingly, reaction with L-selectride only gave $3 \alpha$-alcohol 21, the product of 1,2-reduction, presumably due to steric inaccessibility of $\mathrm{C} 5$.

As so far, all our efforts to process any rearranged material obtained towards swinhoeisterol, and for a further generalization of the radical cascade, next $\gamma$-hydroxy enone 22 which was accessible in 4 steps and $42 \%$ from ergosterol $(1)^{[7]}$ was to be investigated. When treating 22 with $\mathrm{Pb}(\mathrm{OAc})_{4} / \mathrm{I}_{2}$, four main products were obtained after careful separation (Scheme $8 \mathrm{~A}$ ). Once more, two of those contained the diabeo-structure (triene dione 25 and its $15 \beta$-iodo analogue 26); the other two being $13(14 \rightarrow 8)$ abeo dione 23 and its $7 \alpha$-iodo analogue 24 . To further substantiate our mechanistic proposal, $\mathbf{2 3}$ as well as $\mathbf{2 4}$

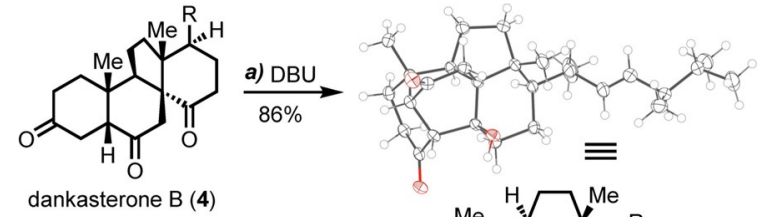

$$
\text { dankasterone B (4) }
$$
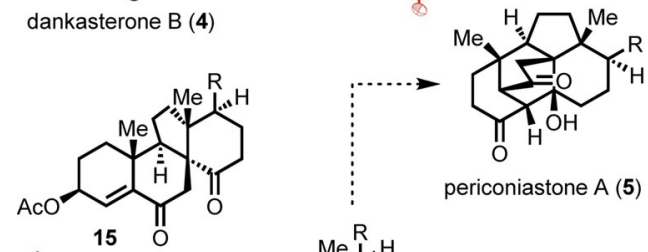

periconiastone $\mathrm{A}(\mathbf{5})$

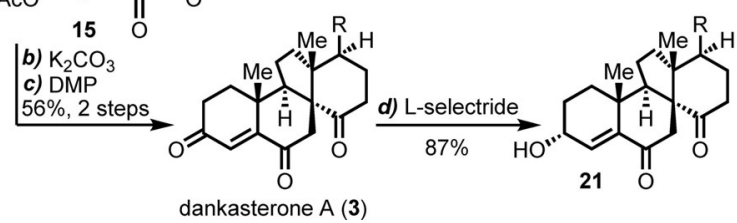

Scheme 7. Synthesis of periconiastone A (5) (ORTEP plot of 5. Thermal ellipsoids are drawn at $50 \%$ probability) and alternative synthetic access to dankasterone A (3) and its reduction. Reagents and conditions: a) DBU (10 equiv.), $\mathrm{PhMe}, 25^{\circ} \mathrm{C}, 12 \mathrm{~h}$; b) $\mathrm{K}_{2} \mathrm{CO}_{3}$ (5.0 equiv.), $\mathrm{MeOH}, 25^{\circ} \mathrm{C}, 1 \mathrm{~h}$; c) DMP (2.0 equiv.), $\mathrm{CH}_{2} \mathrm{Cl}_{2}, 25^{\circ} \mathrm{C}, 1 \mathrm{~h}, 56 \%$ (2 steps); d) L-selectride (2.0 equiv.), THF, $-78^{\circ} \mathrm{C}, 1 \mathrm{~h}, 87 \%$. DBU $=1,8$-diazabicyclo[5.4.0] undec-7-ene DMP = DessMartin periodinane, R as in Scheme 3. CCDC 1989984 contains the supplementary crystallographic data for compound $\mathbf{5}$ (see Experimental Section).
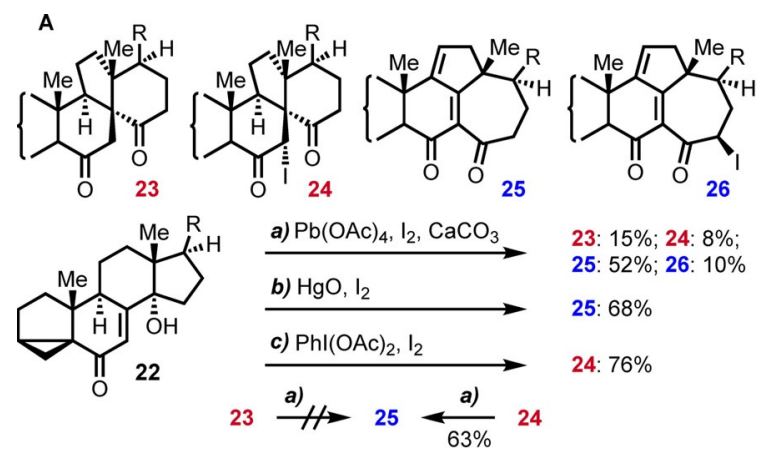

23: $15 \%$; $24: 8 \%$; 25: $52 \% ; 26: 10 \%$ 25: $68 \%$ 24: $76 \%$

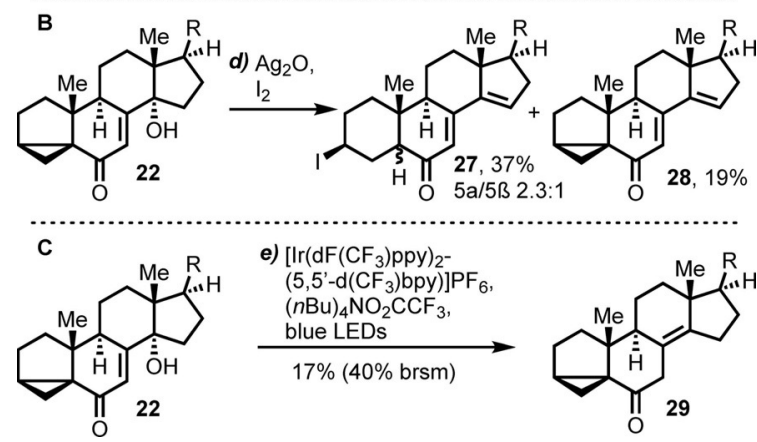

Scheme 8. A: Radical rearrangement of 22 leading to mono- and diabeo structures 23, 24, 25 and 26. B and C: Attempted rearrangements using alternative conditions. Reagents and conditions a) $\mathrm{Pb}(\mathrm{OAc})_{4}\left(2.0\right.$ equiv.), $\mathrm{I}_{2}$ (2.0 equiv.), $\mathrm{CaCO}_{3}$ (2.0 equiv.), $\mathrm{C}_{6} \mathrm{H}_{6}, 85^{\circ} \mathrm{C}, 2 \mathrm{~h}$; b) $\mathrm{HgO}$ (2.7 equiv.), $\mathrm{I}_{2}$ (2.4 equiv.), $\mathrm{C}_{6} \mathrm{H}_{6}, 105^{\circ} \mathrm{C}$ (sealed tube), $2 \mathrm{~h}, 68 \%$; c) $\mathrm{Phl}(\mathrm{OAc})_{2}$ (2.0 equiv.), $\mathrm{I}_{2}$ (1.0 equiv.), $\mathrm{C}_{6} \mathrm{H}_{6}, 25^{\circ} \mathrm{C}, 30 \mathrm{~min}, 76 \%$; d) $\mathrm{Ag}_{2} \mathrm{O}$ (2.0 equiv.), $\mathrm{I}_{2}$ (1.5 equiv.), $\mathrm{C}_{6} \mathrm{H}_{6}$, $85^{\circ} \mathrm{C}, 2$ h, 27: $37 \%(5 \alpha / 5 \beta 2.3: 1), 28: 19 \%$; e) $\left[\operatorname{lr}\left(\mathrm{dF}\left(\mathrm{CF}_{3}\right) \mathrm{ppy}\right)_{2}\left(5,5^{\prime}-\right.\right.$ $\left.\left.\mathrm{d}\left(\mathrm{CF}_{3}\right) \mathrm{bpy}\right)\right] \mathrm{PF}_{6}(3 \mathrm{~mol} \%),\left(n \mathrm{Bu}_{4}\right) \mathrm{NO}_{2} \mathrm{CCF}_{3}$ (0.4 equiv.), blue LEDs, PhMe, $35^{\circ} \mathrm{C}$, $3 \mathrm{~d}, 17 \%$ ( $40 \%$ brsm). brsm $=$ based on recovered starting material, $R$ as is Scheme 3 .

were both separately treated with $\mathrm{Pb}(\mathrm{OAc})_{4} / \mathrm{I}_{2}$. As expected, no conversion of the starting material was observed in case of 
dione 23 , but the reaction of iodide 24 gave rise to $63 \%$ of diabeo-compound 25. As we reported earlier, it was possible to selectively access either the diabeo-framework $\left(25, \mathrm{HgO} / \mathrm{I}_{2}\right.$, $68 \%$ yield) or the monoabeo-skeleton (24, $\mathrm{Phl}(\mathrm{OAc})_{2}, 76 \%$ yield), depending on the conditions to generate the initial alkoxy radical. ${ }^{[13]}$ To test if the rearrangement to the diabeostructures could be initiated without employing toxic $\mathrm{Hg}$ or $\mathrm{Pb}$ reagents, 22 was treated with $\mathrm{Ag}_{2} \mathrm{O}$ and $\mathrm{I}_{2} \cdot{ }^{[20]}$ However, only elimination of the 14-hydroxyl was observed (to give 28) along with partial $i$-steroid opening to give iodide $\mathbf{2 7}$ as a mixture of epimers $(5 \alpha / 5 \beta \quad 2.3: 1) .{ }^{[21]}$ Knowles' photocatalytic ring expansion conditions ${ }^{[22]}$ either did not yield any rearranged product but resulted in the isolation of $\Delta^{8,14}$-steroid 29. ${ }^{[14 a]}$ Any other attempts to initiate a radical-promoted cascade employing other metal salts, did not lead to any conversion of the starting material.

To further study the influence of the stereoconfiguration at C14 on the radical cascade, we prepared14 $\beta$-hydroxy enone 34 (Scheme 9). Since all Riley oxidations carried out resulted in $14 \alpha$-hydroxylation, a Schenck ene reaction followed by reduc-

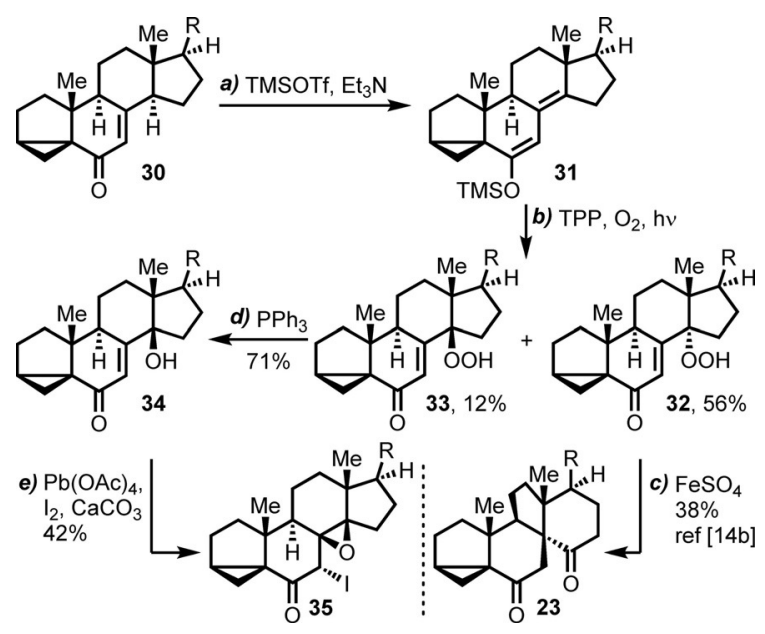

Scheme 9. Synthetic access to $14 \beta-\mathrm{OH} 34$ and attempted rerarrangement. Reagents and conditions: a) TMSOTf (1.5 equiv.), $\mathrm{Et}_{3} \mathrm{~N}$ (2.0 equiv.), $\mathrm{CH}_{2} \mathrm{Cl}_{2}$, $0{ }^{\circ} \mathrm{C}, 1 \mathrm{~h}$; b) TPP $(0.2 \mathrm{~mol} \%), \mathrm{O}_{2}, \mathrm{hv}, \mathrm{CH}_{2} \mathrm{Cl}_{2},-78^{\circ} \mathrm{C}, 15 \mathrm{~min}, 32: 56 \%, 33$ : $12 \%$; c) $\mathrm{FeSO}_{4} \cdot 7 \mathrm{H}_{2} \mathrm{O}$ (1.05 equiv.), acetic buffer ( $\left.\mathrm{pH} 3\right), \mathrm{THF} / \mathrm{H}_{2} \mathrm{O}(1.5: 1), 25^{\circ} \mathrm{C}$, $1 \mathrm{~h}, 38 \%$; d) $\mathrm{PPh}_{3}$ (1.0 equiv.), $\mathrm{CH}_{2} \mathrm{Cl}_{2}, 25^{\circ} \mathrm{C}, 1 \mathrm{~h}, 71 \%$; e) $\mathrm{Pb}(\mathrm{OAc})_{4}$ (2.0 equiv.), $\mathrm{I}_{2}$ (2.0 equiv.), $\mathrm{CaCO}_{3}$ (2.0 equiv.), $\mathrm{C}_{6} \mathrm{H}_{6}, 85^{\circ} \mathrm{C}, 1 \mathrm{~h}, 42 \%$. TMSOTf $=$ trimethylsil$\mathrm{yl}$ trifluoromethanesulfonate, $\mathrm{TPP}=$ meso-tetraphenylporphyrin, $\mathrm{R}$ as in Scheme 3. tion of the hydroperoxide was envisioned, instead. $i$-Steroid enone $\mathbf{3 0}$ was converted into TMS dienol ether $\mathbf{3 1}$, which was then treated with oxygen and TPP as photosensitizer under irradiation with white light to give $14 \alpha$-hydroperoxide 32 and $14 \beta$-hydroperoxide 33 (56 and $12 \%$ yield, respectively). While $14 \alpha-\mathrm{OOH} 32$ could be converted to $13(14 \rightarrow 8)$ abeo-dione 23 in a yield of $38 \%$ using Danieli's conditions $\left(\mathrm{FeSO}_{4}\right)_{1}^{[14 b]} 14 \beta-\mathrm{OOH}$ 33 was reduced to the corresponding alcohol 34, which was then exposed to $\mathrm{Pb}(\mathrm{OAc})_{4} / \mathrm{I}_{2}$. This time, no rearrangement of the steroid skeleton was observed. The alkoxy radical generated at $\mathrm{C} 14$ rather added to the double bond at $\mathrm{C} 8$, giving rise to an epoxide and the $C 7$ centered radical was then quenched by iodine leading to $7 \alpha$-iodo epoxide 35 . This difference in reactivity can be explained with an unfavorable orbital overlap of the radical SOMO and the $\sigma$-orbital of the $\mathrm{C} 13-\mathrm{C} 14$ bond so that no $\beta$ scission could occur.

As the radical rearrangement was most selective on the $i$ steroid system, it was chosen as starting material for our synthetic efforts towards swinhoeisterol A (2) and analogues. In the following, we want to discuss the major synthetic challenges that had to be overcome en route to swinhoeisterol $A$ (Scheme 10). Starting from ergosterol (1), our synthetic approach consisted of an oxidative cleavage/olefination/hydrogenation sequence of $\Delta^{22}$ to introduce the desired (saturated) campestane side chain (Scheme 10, A). We envisioned to introduce the exo-methylene moiety via elimination of a hydroxymethyl group at $\mathrm{C} 4$ at a late stage of the synthesis making use of an enone functionality in the A-ring (Scheme 10, B). This key intermediate was traced back to a diene dione system from our radical cascade (Scheme 10, C).

Following these studies, we attempted a synthetic approach towards swinhoeisterol A (2) making use of 25 (Scheme 11), which was obtained in a good yield from 22 when applying $\mathrm{HgO} / \mathrm{I}_{2}(68 \%)$. It was possible to differentiate the C6- and C14oxo functionalities of diene dione $\mathbf{2 5}$ by selective formation of C14 silyl enol ether 36 . We planned to adjust the oxidation state by 1,6-reduction with L-selectride, which along with the expected reduction involved the incorporation of an oxygen at C9 to give $9 \alpha$-hydroxy dione $\mathbf{3 7}$ presumably through attack of $\mathrm{O}_{2}$ by the intermediary dienolate. Even though this was not the expected product, the synthetic route was continued, since the obtained $9 \alpha$-hydroxy enone pattern is present in swinhoeisterol B (not shown). Reduction with $\mathrm{LiAlH}_{4}$ gave de-silylated $6 \alpha-\mathrm{OH} 38$, which seemed to be a suitable precursor for
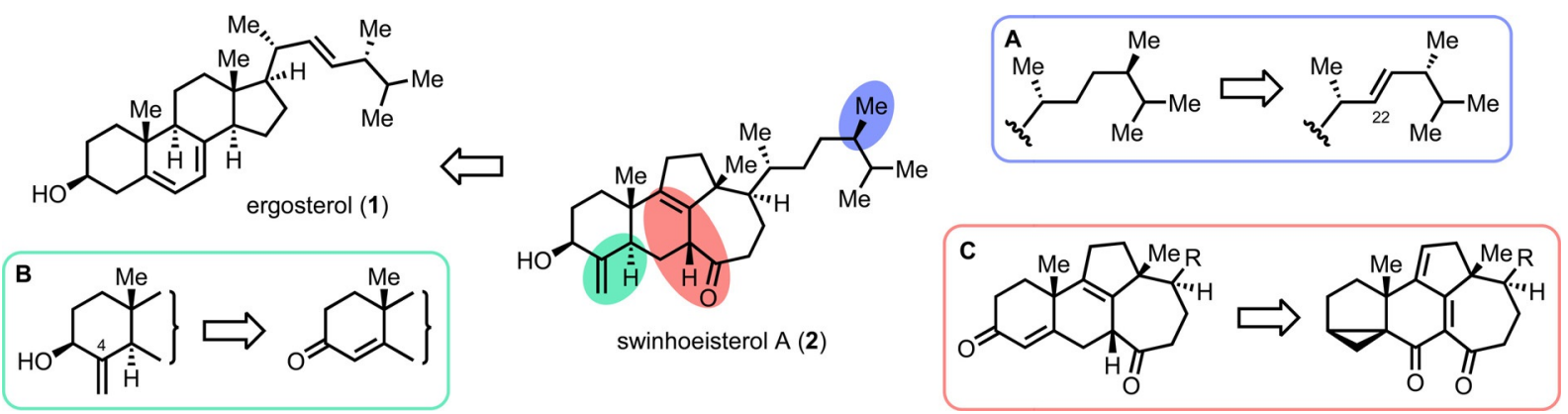

Scheme 10. Analysis of synthetic challenges in swinhoeisterol A (2). 

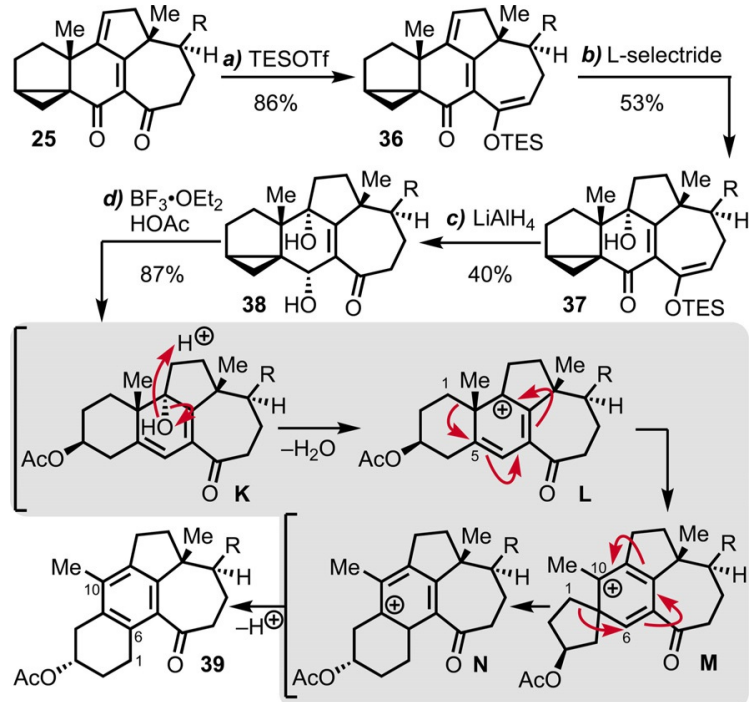

Scheme 11. Transformations on $i$-steroid diene dione $\mathbf{2 5}$ and mechanistic proposal for the formation of anthrasteroid 39. Reagents and conditions: a) TESOTf (5.0 equiv.), 2,6-lutidine (10 equiv.), $\mathrm{CH}_{2} \mathrm{Cl}_{2}, 0^{\circ} \mathrm{C}, 1 \mathrm{~h}, 86 \%$; b) L-selectride (3.0 equiv.), THF, $-78{ }^{\circ} \mathrm{C}, 1 \mathrm{~h}, 53 \%$; c) $\mathrm{LiAlH}_{4}$ (5.0 equiv.). THF, $0^{\circ} \mathrm{C}$ $1 \mathrm{~h}, 40 \%$; d) $\mathrm{BF}_{3} \cdot \mathrm{OEt}_{2} / \mathrm{HOAC} \mathrm{Et}_{2} \mathrm{O}(1: 1: 2), 0^{\circ} \mathrm{C}, 1 \mathrm{~h}, 87 \%$. TESOTf = triethylsilyl trifluoromethanesulfonate, $\mathrm{R}$ as in Scheme 3.

an $i$-steroid opening. However, when treating 38 with acetic acid and $\mathrm{BF}_{3} \cdot \mathrm{OEt}_{21}{ }^{[23]}$ unexpected anthrasteroid ${ }^{[24 a, b]} 39$ was isolated in $87 \%$. Presumably, the initial $i$-steroid opening took place as expected (K) but was followed by generation of cation $\mathbf{L}$ through loss of the hydroxy group. Stabilization of the cation by bond migration could then lead to spiro-compound $\mathbf{M}^{[24 c, d]}$ which, after formation of the C1-C6 bond, gives Wheland complex $\mathbf{N}$. Loss of a proton would generate aromatic 39, whose $1(10 \rightarrow 6)$ abeo-structure can be found in a number of natural products. ${ }^{[24 d-g]}$

Through these experiments, the tertiary alcohol at C9 had been identified to be problematic in the cyclopropane opening reaction of $\mathbf{3 8}$ and, thus, its formation was tried to be avoided by vigorous exclusion of oxygen prior to reduction with L-selectride (Scheme 12). The so-generated $\Delta^{8}$-ene dione system tautomerized (Scheme 10, C), leading to a tedious isolation accompanied by decomposition. To prevent this problem, we decided to add another reducing reagent to the reaction mixture to convert one or both ketones to the corresponding alcohols. Interestingly, the initially formed lithium enolate protected the respective ketone against reduction with lithium aluminum hydride, and only the 6-oxo moiety was reduced to give $\beta$-hydroxy ketone 40. Its treatment with $\mathrm{BF}_{3} \cdot \mathrm{OEt}_{2}$ and acetic acid again resulted in an undesired side reaction, i.e., isomerization of $\Delta^{8}$ into conjugation with the ketone to give $\Delta^{5,7}$-diene 41 as the major product (51\%) and only minor quantities (12\%) of the desired $\Delta^{5,8}$-diene 42. Saponification $\left(\mathrm{K}_{2} \mathrm{CO}_{3}, \mathrm{MeOH}\right)$ proved to be difficult on 42 , and de-acetylation could only be achieved under reductive conditions (DIBAI-H) leading to concomitant reduction of the 14-oxo functionality to furnish $\mathbf{4 3}$. To instead employ $\Delta^{5,7}$-diene $\mathbf{4 1}$, several approaches were investigated, but isomerization of one or both of the two double
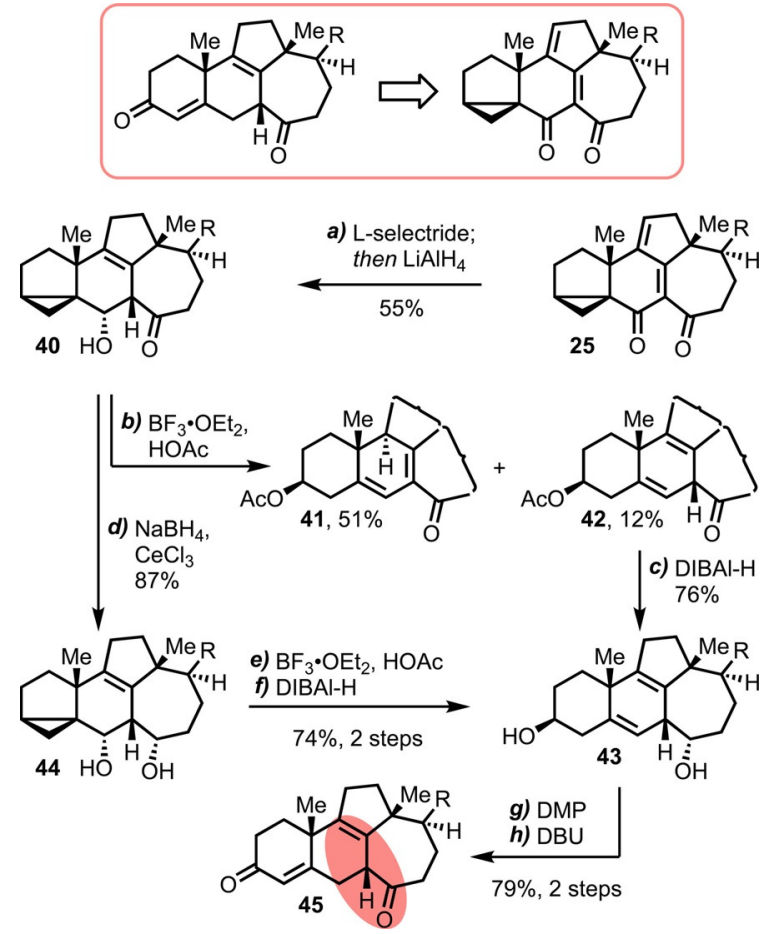

Scheme 12. $i$-Steroid opening and synthesis of key fragment 45. Reagents and conditions: a) L-selectride (1.5 equiv.), $\mathrm{LiAlH}_{4}$ (2.5 equiv.), THF, -78 to $0{ }^{\circ} \mathrm{C}, 2 \mathrm{~h}, 55 \%$; b) $\mathrm{BF}_{3} \cdot \mathrm{OEt}_{2} / \mathrm{HOAC} \mathrm{Et}_{2} \mathrm{O}(1: 1: 2), 0{ }^{\circ} \mathrm{C}, 45 \mathrm{~min}, 41: 51 \%, 42: 12 \%$; c) DIBAl-H, THF, $-78^{\circ} \mathrm{C}, 1.5 \mathrm{~h}, 76 \%$; d) $\mathrm{NaBH}_{4}$ (2.5 equiv.), $\mathrm{CeCl}_{3} \cdot 7 \mathrm{H}_{2} \mathrm{O}$ (2.5 equiv.), $\mathrm{MeOH} / \mathrm{CH}_{2} \mathrm{Cl}_{2}(2: 1),-10{ }^{\circ} \mathrm{C}, 30 \mathrm{~min}, 87 \%$; e) $\mathrm{BF}_{3} \cdot \mathrm{OEt}_{2} / \mathrm{HOAc} \mathrm{Et}_{2} \mathrm{O}$ (1:1:2), 0 to $25^{\circ} \mathrm{C}, 5 \mathrm{~h}, 88 \%$; f) DIBAl-H, THF, $-78^{\circ} \mathrm{C}, 1.5 \mathrm{~h}, 89 \%$; g) DMP, $\mathrm{NaHCO}_{3}, \mathrm{CH}_{2} \mathrm{Cl}_{2}, 25^{\circ} \mathrm{C}, 1 \mathrm{~h}, 82 \%$; h) DBU, $\mathrm{CH}_{2} \mathrm{Cl}_{2}, 25^{\circ} \mathrm{C}, 1 \mathrm{~h}, 91 \%$. DIBAl$\mathrm{H}=$ diisobutylaluminum hydride, $\mathrm{R}$ as in Scheme 3.

bonds proved to be impossible. We suspected that isomerization of $\Delta^{8}$ had occurred due to activation of the ketone with $\mathrm{BF}_{3} \cdot \mathrm{OEt}_{2}$, and, thus, reduced 40 to 6,14-diol 44. Fortunately, this time no isomerization was observed during $i$-steroid opening and subsequent de-acetylation (DIBAI-H) gave 3,14-diol 43 in a convincing yield of $74 \%$ over 2 steps. Employing Oppenauer conditions to achieve oxidation and isomerization to enone 45 did not lead to any conversion. Hence, a stepwise process using Dess-Martin periodinane and then DBU established key-intermediate $\mathbf{4 5}$ with a yield of $79 \%$ over 2 steps.

As a handle to construct the requisite exo-methylene group along with the necessary trans ring junction of the $A$ and $B$ ring (Scheme 10, B), we envisioned the installation of a hydroxymethyl group at C4 and elimination of the primary alcohol to furnish the methylene unit. Initially, we intended to install the remaining carbon atom through a reductive alkylation protocol under dissolving metal conditions. As the direct addition of gaseous formaldehyde did not yield any of the desired hydroxy methylated product, ${ }^{[25]}$ the trapping as a silyl enol ether was investigated. We applied a procedure described by Mueller and Gillick, ${ }^{[26]}$ which involved the generation of socalled lithium bronze. ${ }^{[26 c]}$ Thus, enone $\mathbf{4 5}$ was readily converted into silyl enol ether 46 (Scheme 13). To introduce a suitable methylene precursor, a variety of conditions to alkylate $\mathbf{4 6}$ were tested. Methods using aqueous formaldehyde either in 


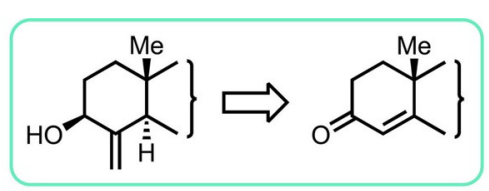

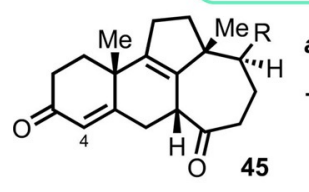
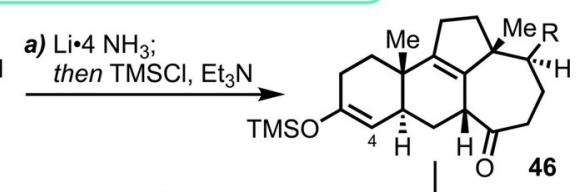

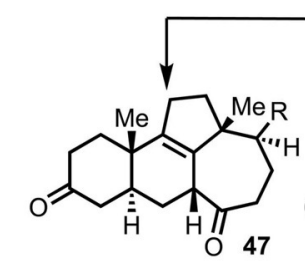

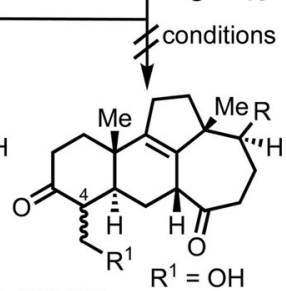

$\mathrm{R}^{1}=\mathrm{OH}$

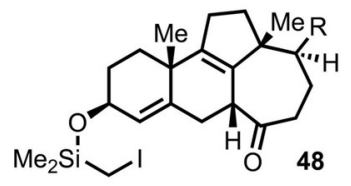

e) $n \mathrm{Bu}_{3} \mathrm{SnCl}, \mathrm{NaBH}_{3} \mathrm{CN}$ AIBN; then $\mathrm{H}_{2} \mathrm{O}_{2}$, KF

48

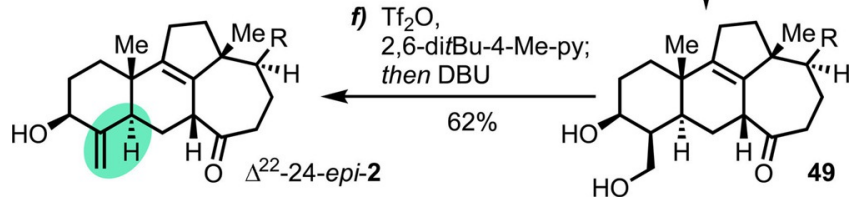

Scheme 13. Attempted reductive alkylation of enone 45 , successful conversion to hydroxymethylated $\mathbf{4 9}$ by Nishiyama-Stork reaction and elimination of the primary alcohol to $\Delta^{22}$-24-epi-2. Reactions and conditions: $\mathrm{Li} \cdot 4 \mathrm{NH}_{3}$, -78 to $25^{\circ} \mathrm{C}$; then $45, \mathrm{THF},-78^{\circ} \mathrm{C}, 30 \mathrm{~min}$; then $\mathrm{TMSCl}^{-\mathrm{Et}_{3} \mathrm{~N}}(1: 2),-60$ to $-20^{\circ} \mathrm{C}, 1 \mathrm{~h}$; b) $\mathrm{NaBH}_{4}$ (0.6 equiv.), $\mathrm{CeCl}_{3} \cdot 7 \mathrm{H}_{2} \mathrm{O}$ (1.5 equiv.), $\mathrm{MeOH},-10{ }^{\circ} \mathrm{C}$, $20 \mathrm{~min}$; c) (chloromethyl)-chlorodimethylsilane (5.0 equiv.), $\mathrm{Et}_{3} \mathrm{~N}$ (10 equiv.), $\operatorname{DMAP}\left(0.2\right.$ equiv.), $\mathrm{CH}_{2} \mathrm{Cl}_{2}, 25^{\circ} \mathrm{C}, 1 \mathrm{~h}$; d) Nal (50 equiv.), acetone, $60^{\circ} \mathrm{C}, 16 \mathrm{~h}$, $83 \%$ (3 steps); e) $n \mathrm{Bu}_{3} \mathrm{SnCl}$ ( 0.2 equiv.), $\mathrm{NaBH}_{3} \mathrm{CN}$ (2.0 equiv.), $\mathrm{AIBN}$ ( 0.1 equiv.), $t \mathrm{BuOH}, 85^{\circ} \mathrm{C}, 16 \mathrm{~h}$; then $\mathrm{KF}$ (10 equiv.), $\mathrm{KHCO}_{3}$ (10 equiv.), $\mathrm{H}_{2} \mathrm{O}_{2} /$ $\mathrm{MeOH} / \mathrm{THF}$ (2:2:1), $25^{\circ} \mathrm{C}, 30 \mathrm{~min}, 36 \%$; ) $\mathrm{Tf}_{2} \mathrm{O}$ (2.5 equiv.), 2,6-di-tert-butyl-4methylpyridine (7.5 equiv.), $\mathrm{CH}_{2} \mathrm{Cl}_{2},-78^{\circ} \mathrm{C}, 5 \mathrm{~min}$; then $\mathrm{MeOH}$ (30 equiv.), DBU (20 equiv.), -78 to $25^{\circ} \mathrm{C}, 2 \mathrm{~h}, 62 \%$. TMS = trimethylsilyl, DMAP $=4$-(dimethylamino)pyridine, AIBN=2,2'-azobis(isobutyronitrile), $\mathrm{Tf}=$ trifluoromethanesulfonyl, $\mathrm{R}$ as in Scheme 3.

combination with Lewis acids such as $\mathrm{Sc}(\mathrm{OTf})_{3}{ }^{[27]}$ or $\mathrm{Yb}(\mathrm{OTf})_{3}{ }^{[28]}$ or by addition of a de-silylating reagent (e.g., $\operatorname{TBAF}^{[29]}$ ) have been described. Even though addition of formaldehyde could be detected by mass spectrometry, the isolation of the desired $\gamma$-hydroxy ketone was unsuccessful and instead, ketone $\mathbf{4 7}$ was obtained, the product of a retro-aldol reaction. ${ }^{[30]}$ To circumvent this problem, we attempted to install a protected hydroxy methyl moiety. However, when treating silyl enol ether 46 with $\mathrm{BOMCl}$ and varying Lewis acids, ${ }^{[31]}$ only $\alpha$-halogenated ketones were isolated, yielding 4-chloro- and 4-fluoro-ketones when using $\mathrm{SnCl}_{4}, \mathrm{TiCl}_{4}$, or $\mathrm{BF}_{3} \cdot \mathrm{OEt}_{2}$, respectively. Consequently, the introduction of other functional groups known to be convertible into a methylene group was considered. Thus, treatment of silyl enol ether $\mathbf{4 6}$ with ethyl bromo acetate to give the corresponding ethyl ester ${ }^{[26 b]}$ or Eschenmoser's salt to give the dimethylamine, ${ }^{[32]}$ were attempted but did not yield any desired product other than ketone $\mathbf{4 7}$.

Alternatively, the method by Nishiyama and Stork ${ }^{[33]}$ was considered and successfully executed to introduce the C4 hy- droxymethyl moiety. Thus, enone $\mathbf{4 5}$ was selectively reduced under Luche conditions to the corresponding allylic alcohol, which was then treated with chloro(bromomethyl)dimethylsilane and triethyl amine to give the crucial precursor for a radical cyclization. Initial results employing the (bromomethyl)silyl ether (not shown) in the radical cyclization and subsequent Tamao oxidation ${ }^{[34]}$ lacked reproducibility. An alternative procedure employing substoichiometric amounts of the tin reagent required the corresponding (iodomethyl)silyl ether $48^{[35]}$ Hence, allylic alcohol was converted to the (chloromethyl)silyl ether (not shown) followed by Finkelstein reaction to give iodide 48. Radical cyclization was then achieved by treatment with catalytic quantities of AIBN and ${n B u_{3}}_{3} \mathrm{SnCl}$ and stoichiometric amounts of $\mathrm{NaBH}_{3} \mathrm{CN}$ to result in the formation of a oxasilolane (not shown), which, upon oxidative work up $\left(\mathrm{H}_{2} \mathrm{O}_{2}\right.$, $\mathrm{KF}$ ), delivered diol 49 in $36 \%$ yield along with $16 \%$ of its undesired $5 \beta$-epimer. Finally, the primary alcohol was converted to the corresponding triflate with $\mathrm{Tf}_{2} \mathrm{O}$ at $-78^{\circ} \mathrm{C}$, which, upon warming to $25^{\circ} \mathrm{C}$, eliminated to yield the desired exo-methylene group in $\Delta^{22}$-24-epi-swinhoeisterol $A \Delta^{22}$-24-epi-2. ${ }^{[37]}$

With a reliable route for swinhoeisterol A's tetracyclic core, one last synthetic challenge had to be overcome, i.e., the introduction of the correctly configurated side chain (Scheme 10, A). It was deemed strategically advantageous, to perform the necessary modifications at a late stage. Since we envisioned a sequence of oxidative $\mathrm{C}-\mathrm{C}$ bond cleavage, olefination, and hydrogenation, many synthetic intermediates bearing easily accessible double bonds additional to $\Delta^{22}$ had to be excluded a priori. Thus, hydroxymethylated 49 and enone 45 presented themselves as promising candidates (Scheme 14). Oxidative $\Delta^{22}$ bond cleavage on the stage of diol $\mathbf{4 9}$ was achieved through ozonolysis and reductive workup. Attempted Julia-Kocienski olefination proved unsuccessful due to low solubility of the starting material. Thus, the 1,3-diol functionality of $\mathbf{4 9}$ was protected as an acetonide, which was processed to the corresponding aldehyde. Again, no conversion of the starting material in an attempted Julia-Kocienski reaction could be observed. We, thus, shifted our attempts towards enone 45. Ozonolysis gave aldehyde $\mathbf{5 0}$, and this time, Julia-Kocienski olefination using sulfone $\mathbf{5 1}$ indeed led to conversion of starting material. Unfortunately, not the desired olefin, but tetrazole 52, which presumably arose from aldol reaction between enolizable $\mathrm{C7}$ and the 22-oxo functionality followed by trapping of the alcoholate by the tetrazole moiety of sulfone $\mathbf{5 1}$, was isolated. As a consequence of this reactivity, $i$-steroid diol 44, an intermediate without the oxo moiety at C14, was anticipated to adopt a less reactive conformation and, thus, seemed to be a better choice. However, treatment of the corresponding aldehyde of diol $\mathbf{4 4}$ with LiHMDS and sulfone $\mathbf{5 1}$ only led to isolation of material with the C6 hydroxyl bearing a tetrazole substituent. One of the few remaining intermediates to conduct the ozonolysis/olefination approach was $\beta$-hydroxy ketone 40, which, after conversion to aldehyde $\mathbf{5 3}$ eventually afforded the desired olefin 55 (with the double bond being $Z$ configurated) along with small quantities of aldol product 54 . Fortunately, it was possible to almost suppress formation of $\mathbf{5 4}$ (less than $5 \%$ ) when increasing the amount of sulfone 51 (5.0 equiv.). 

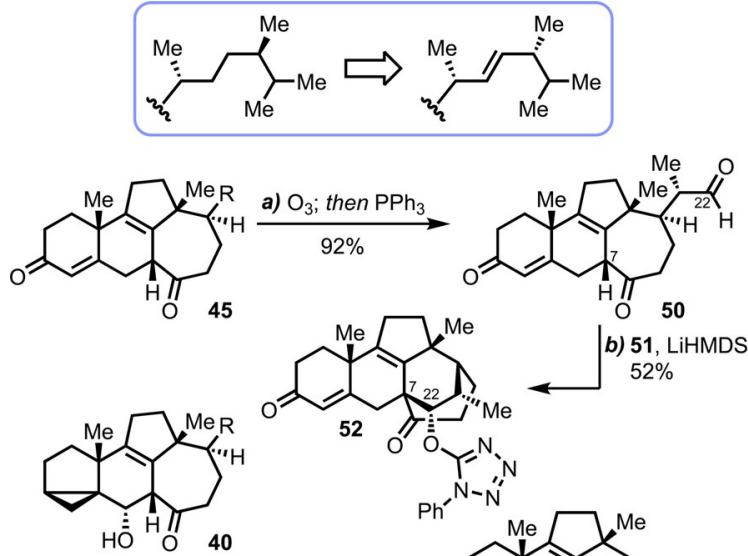<smiles>COc1nnnn1P</smiles>
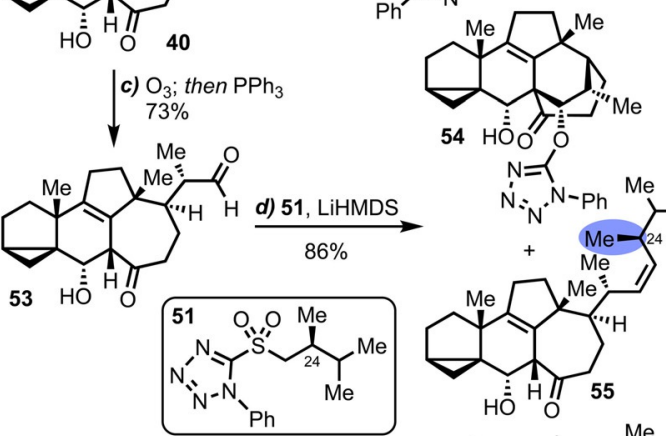

54 $\mathrm{N}=$
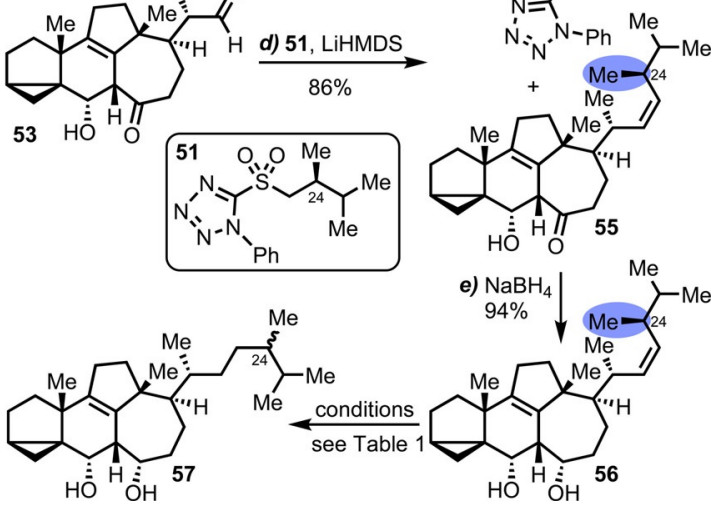

Scheme 14. Attempts to install the necessary campestane side chain. Reagents and conditions: a) $\mathrm{O}_{3}, \mathrm{CH}_{2} \mathrm{Cl}_{2}$ /pyridine $(99: 1),-78^{\circ} \mathrm{C}, 3 \mathrm{~min}$; then $\mathrm{PPh}_{3}$ (1.1 equiv), -78 to $25^{\circ} \mathrm{C}, 16 \mathrm{~h}, 92 \%$; b) 51 (5.0 equiv.), LiHMDS (5.0 equiv.), $\mathrm{THF},-78$ to $25^{\circ} \mathrm{C}, 22 \mathrm{~h}, 52 \%$; c) $\mathrm{O}_{3}, \mathrm{CH}_{2} \mathrm{Cl}_{2} /$ pyridine (99:1), $-78{ }^{\circ} \mathrm{C}, 45 \mathrm{~min}$; then $\mathrm{PPh}_{3}$ (2.0 equiv.), -78 to $25^{\circ} \mathrm{C}, 16 \mathrm{~h}, 73 \%$; d) 51 (5.0 equiv), LiHMDS (3.1 equiv), THF, -78 to $-65^{\circ} \mathrm{C}, 2 \mathrm{~h}, 86 \%$; e) $\mathrm{NaBH}_{4}$ (2.5 equiv), $\mathrm{CH}_{2} \mathrm{Cl}_{2} / \mathrm{MeOH}(1: 1),-10^{\circ} \mathrm{C}, 30 \mathrm{~min}, 94 \%$. $\mathrm{HMDS}=1,1,1,3,3,3-$ hexamethyldisilazide, $\mathrm{R}$ as in Scheme 3.

That way, olefin $\mathbf{5 5}$ was obtained in $86 \%$ yield. To furnish the desired saturated campestane side chain, hydrogenation conditions were tested on olefin 55, but no conversion of starting material was observed under the conditions employed. Further reduction experiments were then carried out on diol 56, which was obtained by reduction with $\mathrm{NaBH}_{4}$.

Hydrogenation of a $22 Z$ double bond is known to be more difficult than of the corresponding $22 E$ isomer. ${ }^{[37]}$ In agreement, in most experiments no conversion was achieved (Table 1, entries 3-9) and only elevated hydrogen pressure (40-60 bar) led to complete conversion to $\mathbf{5 7}$. Unfortunately, varying degrees of epimerization at C24 occurred during the course of this reaction $^{[38]}$ yielding up to $50 \%$ of the undesired ergostane product when using $\mathrm{Pd} / \mathrm{C}$ (entry 1 ) and still $25 \%$ when $\mathrm{Pt} / \mathrm{C}$ was used (entry 2). Attempted alternatives, such as Wilkinson's (entry 6) or Crabtree's catalyst (entry 7) as well as Shenvi's radical hydrogenation method (entries 8 and 9 ) $^{[39]}$ did not lead to any conversion of starting material.

As hydrogenation of a $22 E$-configurated double bond without epimerization of C24 was deemed more promising, we car-

\begin{tabular}{|c|c|c|c|c|}
\hline Entry & Catalyst & Pressure $\mathrm{H}_{2}$ [bar] & Epimerization at $\mathrm{C} 24^{[\mathrm{a}]}$ & Conversion \\
\hline 1 & $\mathrm{Pd} / \mathrm{C}$ & 40 & $\approx 50 \%$ & complete \\
\hline 2 & $\mathrm{Pt} / \mathrm{C}$ & 40 & $\approx 25 \%$ & complete \\
\hline 3 & $\mathrm{PtO}_{2}$ & 60 & - & none \\
\hline 4 & Ir & 60 & - & none \\
\hline 5 & $\mathrm{Rh} / \mathrm{C}$ & 60 & - & none \\
\hline 6 & {$\left[\mathrm{RhCl}\left(\mathrm{PPh}_{3}\right)_{3}\right]$} & 60 & - & none \\
\hline 7 & Crabtree $^{[b]}$ & 60 & - & none \\
\hline 8 & $\mathrm{Mn}(\mathrm{dpm})_{3}$ & $-[c]$ & - & none \\
\hline 9 & $\mathrm{Co}(\mathrm{acac})_{2}$ & $-[c]$ & - & none \\
\hline
\end{tabular}

[a] Ratio of epimers determined from ${ }^{13} \mathrm{C}$ NMR spectra (see Supporting Information of Ref. [13]). [b] Crabtree catalyst: (SP-4)tris(cyclohexyl)phosphane[(1-2- $\eta: 5-6-\eta)$-cycloocta-1,5-diene]pyridineiridium hexafluorophosphate. [c] 4.0 equiv. of $\mathrm{PhSiH}_{3}$; acac $=$ acetylacetonate, $\mathrm{dpm}=2,2,6,6$-tetramethyl-3,5-heptanedionato.

ried out several isomerization experiments to convert $22 Z$ to $22 E$, but could eventually not succeed in identifying a viable method. At this point, we turned our attention to rather functionalize the side chain double bond and remove the thus-installed functional group reductively in a separate step. Introduction of sulfur-containing functionalities failed and halogenation with bromine to the dibromide and subsequent treatment with $\mathrm{AIBN} / n \mathrm{Bu}_{3} \mathrm{SnH}$ only led to a mixture of $22 \mathrm{E}$ - and 22Z-diol 56. To our delight, hydroboration and subsequent oxidation with $\mathrm{NaOH} / \mathrm{H}_{2} \mathrm{O}_{2}$ afforded primarily a 6,14,23-triol (not shown) under concomitant reduction of C14. Acetonide formation of the thus-obtained 1,3-diol unit and functionalization of the side chain alcohol (predominantly $23-\mathrm{OH}$ ) to a xanthate, followed by Barton-McCombie deoxygenation eventually gave the desired saturated campestane side chain without any epimerization (Scheme 15).

All synthetic challenges were thus coped with so that rather similar approaches led to the synthesis of natural swinhoeisterol A (2, b-series) and 24-epi-swinhoeisterol A (24-epi-2, a-series). As it was initially uncertain at which stage an installation of the correct side chain fragment would be feasible, the synthetic route had also been carried out in the ergostane series, starting from ergosterol (1) without hydrogenation of the $\Delta^{22}$ bond. This route enabled access to $\Delta^{22}$-24-epi-swinhoeisterol $A$ $\left(\Delta^{22}-24-e p i-2\right)$ in 16 steps and a total yield of $1.5 \%$.

In summary, access to the diabeo-skeleton ( 25 and 25 a) via $\gamma$-hydroxy enones $\mathbf{2 2}$ or $\mathbf{2 2}$ a was accomplished in five to six steps, respectively, starting from ergosterol (1). $\beta$-Hydroxy ketones $\mathbf{4 0}$ and $\mathbf{4 0} \mathrm{a}$, obtained after reduction, were further processed following two different pathways. For the synthesis of swinhoeisterol A (2), 40a was subjected to ozonolysis and Julia-Kocienski olefination to give $\mathbf{5 5} \mathbf{b}$, followed by a hydroboration, oxidation/Barton-McCombie deoxygenation sequence to yield the desired saturated campestane side chain as in $58 \mathrm{~b}$. Opening of the $i$-steroid moiety led to acetate $59 \mathrm{~b} . \mathbf{4 0}$ and $40 \mathrm{a}$, on the other hand, were reduced to diols 44 and $44 \mathrm{a}$ and subsequent treatment with $\mathrm{BF}_{3} \cdot \mathrm{OEt}_{2}$ under acidic conditions gave the corresponding acetates 59 and $59 \mathrm{a}$. De-acetylation was accomplished using DIBAI-H giving rise to $43,43 \mathrm{a}$, and $43 \mathrm{~b}$. Oxidation with DMP and subsequent isomerization 
<smiles>[R]C1CC[C@H]2C3=CC=C4C[C@@H](O)CC[C@]4(C)[C@H]3CC[C@]12C</smiles>

(-)-ergosterol (1)

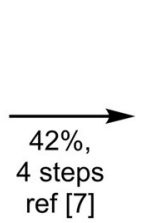

ef [7]

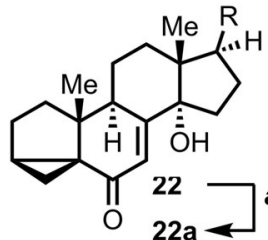

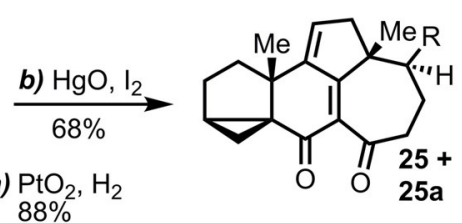

c) L-selectride: then $\mathrm{LiAlH}_{4}$ $54-55 \%$

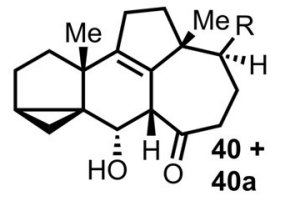

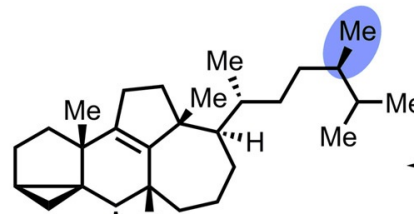

f) $\mathrm{BH}_{3} \cdot \mathrm{THF}$; then $\mathrm{H}_{2} \mathrm{O}_{2}, \mathrm{NaOH}$ g) $(\mathrm{MeO})_{2} \mathrm{CMe}_{2}$

h) KHMDS, $\mathrm{CS}_{2}$; then $\mathrm{Mel}$ i) $\mathrm{nBu}_{3} \mathrm{SnH}, \mathrm{AIBN}$

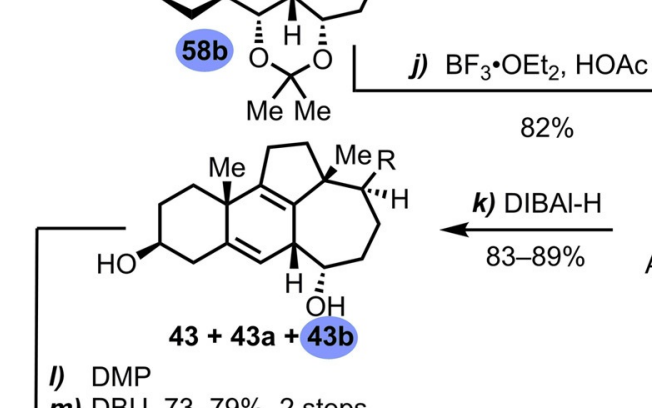
$54 \%, 4$ steps

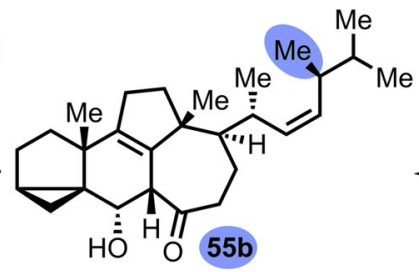

d) $\mathrm{O}_{3}$; then $\mathrm{PPh}_{3}$ e) 51, LiHMDS $63 \%, 2$ steps

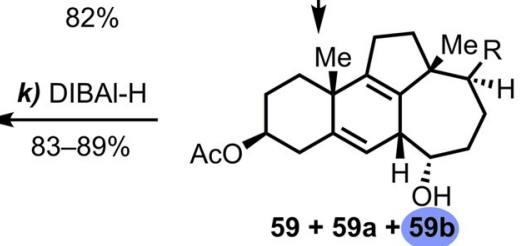

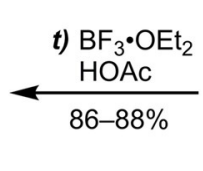

$59+59 a+59 b$

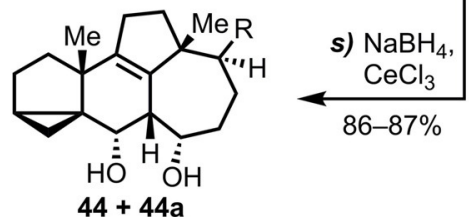

m) DBU, $73-79 \%, 2$ steps

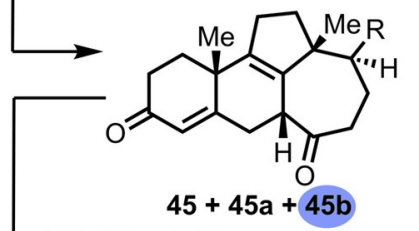

u) $\mathrm{NaBH}_{4}, \mathrm{CeCl}_{3}$

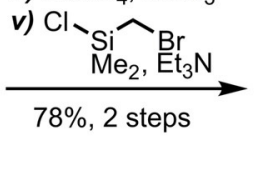

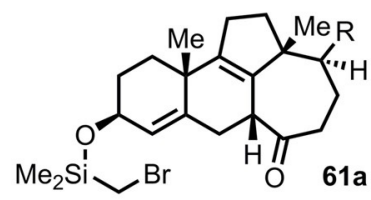

w) $n \mathrm{Bu}_{3} \mathrm{SnH}, \mathrm{AIBN}$;
then $\mathrm{H}_{2} \mathrm{O}_{2}, \mathrm{KF}$

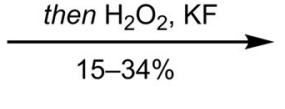

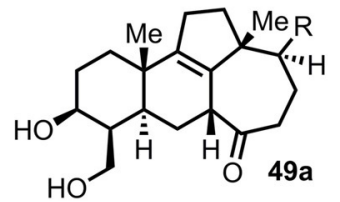

n) $\mathrm{NaBH}_{4}, \mathrm{CeCl}_{3}$<smiles>NC[SiH2][SiH2]C[SiH2]Cl</smiles>

$71-83 \%, 2$ steps

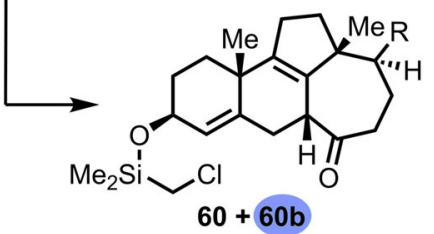

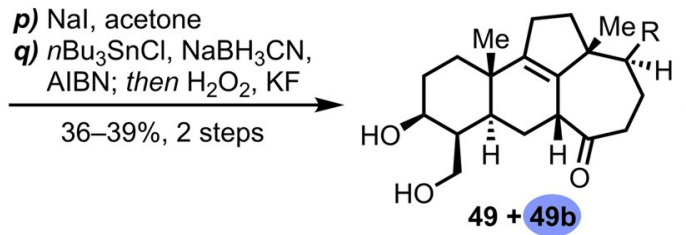

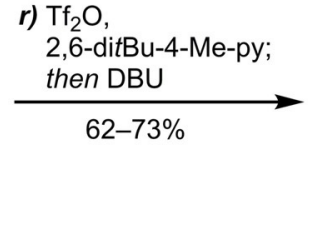

x) $\mathrm{Tf}_{2} \mathrm{O}$ 2,6-lutidine
then DBU $72 \%$<smiles>C1CCCCC1</smiles>

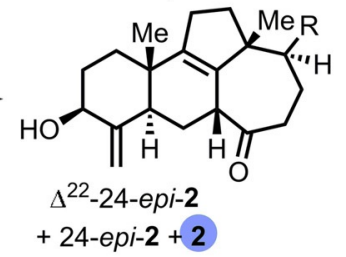<smiles>[R]CC(C)(C)[C@@H](C)C=C[C@@H](C)C(C)C</smiles>

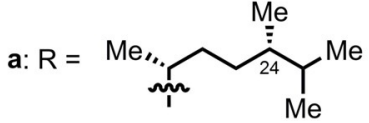

b: $R=M_{\text {in }} \underbrace{M e}_{{ }_{24}} M e$<smiles>CC(C)C(C)(C)CSOC(=O)O</smiles>

Scheme 15. Overview of the synthetic routes to swinhoeisterol A (2, b series), 24-epi-swinhoeisterol A (24-epi-2, a series) and $\Delta^{22}$-24-epi-swinhoeisterol A ( $\Delta^{22}$ 24-epi-2) starting from ergosterol (1). Reactions and conditions: a) $\mathrm{PtO}_{2}\left(0.1\right.$ equiv.), $\mathrm{H}_{2}\left(20\right.$ bar), EtOAc, $25^{\circ} \mathrm{C}, 24 \mathrm{~h}, 22 \mathrm{a}: 88 \%$; b) $\mathrm{HgO}$ (2.7 equiv.), $\mathrm{I}_{2}(2.4 \mathrm{equiv}$.), $\mathrm{C}_{6} \mathrm{H}_{6}, 105^{\circ} \mathrm{C}, 2 \mathrm{~h}, 25: 68 \%, 25 \mathrm{a}: 68 \%$; c) L-selectride (2.0 equiv.), THF, $-78^{\circ} \mathrm{C}, 1 \mathrm{~h}$; then $\mathrm{LiAlH}_{4}$ (2.0 equiv.), -78 to $0{ }^{\circ} \mathrm{C}, 1 \mathrm{~h}, 40: 55 \%, 40 \mathrm{a}: 54 \%$; d) $\mathrm{O}_{3}, \mathrm{CH}_{2} \mathrm{Cl}_{2} /$ pyridine (99:1), $-78^{\circ} \mathrm{C}, 45 \mathrm{~min}$; then $\mathrm{PPh}_{3}\left(2.0\right.$ equiv.), -78 to $25^{\circ} \mathrm{C}$, $16 \mathrm{~h}$; e) 51 (5.0 equiv.), LiHMDS (3.1 equiv.), THF, $-65^{\circ} \mathrm{C}, 1 \mathrm{~h}$; then $40,-65^{\circ} \mathrm{C}, 1 \mathrm{~h}, 55 \mathrm{~b}$ : $63 \%$ (2 steps); f) $\mathrm{BH}_{3} \cdot \mathrm{THF}$ (10 equiv.), $\mathrm{THF}, 0$ to $25^{\circ} \mathrm{C}$, $16 \mathrm{~h}$; then $\mathrm{NaOH} / \mathrm{H}_{2} \mathrm{O}_{2}(1: 1), 25^{\circ} \mathrm{C}, 1 \mathrm{~h}$; g) $\mathrm{CSA}\left(1.2\right.$ equiv.), $\left(\mathrm{MeO}_{2} \mathrm{CMe}_{2} / \mathrm{CH}_{2} \mathrm{Cl}_{2}(1: 5), 0^{\circ} \mathrm{C}, 1 \mathrm{~h} ; \mathrm{h}\right) \mathrm{KHMDS}$ (2.0 equiv.), $\mathrm{CS}_{2}$ (5.0 equiv.), THF, -78 to $25^{\circ} \mathrm{C}, 1.5 \mathrm{~h}$; then Mel (7.5 equiv.), $25^{\circ} \mathrm{C}, 45 \mathrm{~min}$; i) AlBN (0.5 equiv.), $n \mathrm{nu}_{3} \mathrm{SnH}\left(5.0\right.$ equiv.), $\mathrm{C}_{6} \mathrm{H}_{6}, 85^{\circ} \mathrm{C}, 3 \mathrm{~h}, 58 \mathrm{~b}: 54 \%$

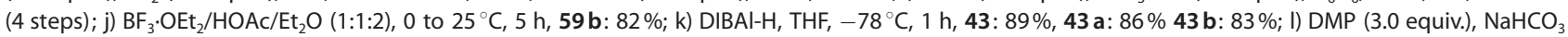
(6.6 equiv.), $\mathrm{CH}_{2} \mathrm{Cl}_{2}, 25^{\circ} \mathrm{C}, 1 \mathrm{~h}$; m) DBU (0.2 equiv.), $\mathrm{CH}_{2} \mathrm{Cl}_{2}, 25^{\circ} \mathrm{C}, 1 \mathrm{~h}, 45: 75 \%$ (2 steps), 45 a: $79 \%$ (2 steps), 45 b: $73 \%$ (2 steps); n) $\mathrm{NaBH}_{4}(0.6$ equiv.), $\mathrm{CeCl}_{3} \cdot 7 \mathrm{H}_{2} \mathrm{O}$ (2.5 equiv.), $\mathrm{MeOH}_{2}-10^{\circ} \mathrm{C}, 20 \mathrm{~min}$; o) chloro(chloromethyl)dimethylsilane (5.0 equiv.), $\mathrm{Et}_{3} \mathrm{~N}$ (10 equiv.), DMAP $\left(0.2\right.$ equiv.), $\mathrm{CH}_{2} \mathrm{Cl}_{2}, 25^{\circ} \mathrm{C}, 1 \mathrm{~h}, 60$ : $83 \%$ (2 steps), 60 b: $71 \%$ (2 steps); p) Nal (50 equiv.), acetone, $60^{\circ} \mathrm{C}, 16 \mathrm{~h}$; q) $n \mathrm{Bu}_{3} \mathrm{SnCl}\left(0.2\right.$ equiv.), $\mathrm{NaBH}_{3} \mathrm{CN}\left(2.0\right.$ equiv.), $\mathrm{AlBN}\left(0.1\right.$ equiv.), $t \mathrm{BuOH}, 85^{\circ} \mathrm{C}, 16 \mathrm{~h}$; then $\mathrm{KF}$ (10 equiv.), $\mathrm{KHCO}_{3}$ (10 equiv.), $\mathrm{H}_{2} \mathrm{O}_{2} / \mathrm{MeOH} / \mathrm{THF}$ (2:2:1), $25^{\circ} \mathrm{C}, 30 \mathrm{~min}, 49: 36 \%$ (2 steps), 49 b: $39 \%$ (2 steps); r) Tf $2 \mathrm{O}$ (2.5 equiv.), 2,6-di-tbutyl-4-methylpyridine (7.5 equiv.), $\mathrm{CH}_{2} \mathrm{Cl}_{2},-78{ }^{\circ} \mathrm{C}, 5 \mathrm{~min}$; then $\mathrm{MeOH}$ (30 equiv.), DBU (20 equiv.), -78 to $25^{\circ} \mathrm{C}, 2 \mathrm{~h}, \Delta^{22}-24-e p i-2: 62 \%, 2: 73 \%$; s) $\mathrm{NaBH}_{4}(2.5$ equiv.),

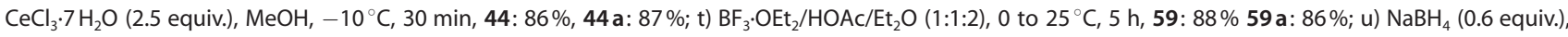
$\mathrm{CeCl}_{3} \cdot 7 \mathrm{H}_{2} \mathrm{O}$ (2.5 equiv.), $\mathrm{MeOH},-10{ }^{\circ} \mathrm{C}, 20$ min; v) (bromomethyl)chlorodimethylsilane (15 equiv.), $\mathrm{Et}_{3} \mathrm{~N}$ (20 equiv.), DMAP $\left(0.2\right.$ equiv.), $\mathrm{CH}_{2} \mathrm{Cl}_{2}, 25^{\circ} \mathrm{C}, 1 \mathrm{~h}, 61 \mathrm{a}:$ $78 \%$ (2 steps); w) AIBN (1.0 equiv.), $n \mathrm{Bu}_{3} \mathrm{SnH}$ (5.0 equiv.), $\mathrm{C}_{6} \mathrm{H}_{6}, 85^{\circ} \mathrm{C}, 16 \mathrm{~h}$; then $\mathrm{KF}\left(10\right.$ equiv.), $\mathrm{KHCO}_{3}$ (10 equiv.), $\mathrm{H}_{2} \mathrm{O}_{2} / \mathrm{MeOH} / \mathrm{THF}(2: 2: 1), 25^{\circ} \mathrm{C}, 2.5 \mathrm{~h}, 49 \mathrm{a}: 15-$ $34 \% ; \mathrm{x}) \mathrm{Tf}_{2} \mathrm{O}$ (10 equiv.), 2,6-lutidine (15 equiv.), $\mathrm{CH}_{2} \mathrm{Cl}_{2},-78^{\circ} \mathrm{C}, 10 \mathrm{~min}$; then $\mathrm{MeOH}$ (10 equiv.), DBU (20 equiv.), -78 to $25^{\circ} \mathrm{C}, 1.5 \mathrm{~h}, 24-$ epi-2: $72 \%$. CSA $=$ camphorsulfonic acid, py $=$ pyridine, $\mathrm{PT}=1$-phenyl- $1 \mathrm{H}$-tetrazol-5-yl. 
of the $\Delta^{5}$ bond with DBU yielded enones $45,45 a$, and $45 \mathrm{~b}$. Luche reduction and silylation with (chloromethyl)- or (bromomethyl)chlorodimethylsilane gave (chloromethyl)silyl ethers 60 and $60 \mathrm{~b}$, and (bromomethyl)silyl ether $61 \mathrm{a}$, respectively. As classic Nishiyama-Stork conditions (61a, AIBN, nBuSnH) followed by Tamao oxidation gave crucial diol 49 a only in low and varying yields (15-34\%), we adjusted the synthetic route towards $\Delta^{22}$-24-epi-2 and 2. (Chloromethyl)silyl ethers 60 and $60 \mathrm{~b}$ were transformed to the corresponding (iodomethyl)silyl ethers using Finkelstein conditions and then treated with catalytic amounts of AIBN and $n \mathrm{Bu}_{3} \mathrm{SnCl}$ and a stoichiometric amount of $\mathrm{NaBH}_{3} \mathrm{CN}$ prior to oxidation, facilitating a reliable access to diols 49 and $49 \mathrm{~b}$. Finally, triflation of the primary alcohol and subsequent elimination afforded 2, 24-epi-2, and $\Delta^{22}$-24-epi-2, respectively, bearing the characteristic exo-methylene group of the swinhoeisterols.

\section{Conclusion}

We herein detailed our efforts towards the synthesis of swinhoeisterol A (2) and discussed major challenges that were overcome during the development of a viable synthetic route. Additionally, the synthesis of the first analogue, $\Delta^{22}$-24-episwinhoeisterol A ( $\Delta^{22}$-24-epi-2) was outlined as well as several experiments that were carried out to support our mechanistic proposal for the radical framework reconstruction. Two unexpected rearrangements of the steroid skeleton were observed, one of them leading to hydroxy lactone 20, which had not been reported before. The synthesis of the remaining members of the swinhoeisterol class and the biological evaluation of all synthesized natural products are ongoing in our laboratory.

\section{Experimental Section}

Crystallographic data: Deposition numbers 1989984 (5), 1991055 (9), and 1991054 (10) contain the supplementary crystallographic data for this paper. These data are provided free of charge by the joint Cambridge Crystallographic Data Centre and Fachinformationszentrum Karlsruhe Access Structures service.

\section{Acknowledgements}

Financial support for this work was provided by Deutsche Forschungsgemeinschaft (Grant No. HE 7133/7-1), the Boehringer Ingelheim Stiftung (exploration grant to P.H.), and Studienstiftung des Deutschen Volkes (Ph.D. scholarship to R.C.H.). We acknowledge the assistance of the Core Facility BioSupraMol supported by the DFG.

\section{Conflict of interest}

The authors declare no conflict of interest.

Keywords: biomimetic synthesis - natural product synthesis radical reactions $\cdot$ rearrangement $\cdot$ steroids
[1] a) R. Ebel, Mar. Drugs 2010, 8, 2340-2368; b) M. E. Rateb, R. Ebel, Nat Prod. Rep. 2011, 28, 290-344; c) J. W. Blunt, B. R. Copp, R. A. Keyzers, M. H. G. Munro, M. R. Prinsep, Nat. Prod. Rep. 2014, 31, 160-258.

[2] a) X. Wang, Z. Ma, J. Lu, X. Tan, C. Chen, J. Am. Chem. Soc. 2011, 133, 15350-15353; b) H. C. Lam, J. T. J. Spence, J. H. George, Angew. Chem. Int. Ed. 2016, 55, 10368-10371; Angew. Chem. 2016, 128, 10524-10527; c) Y. Wang, W. Ju, H. Tian, W. Tian, J. Gui, J. Am. Chem. Soc. 2018, 140, 9413-9416; d) Y. Wang, B. Chen, X. He, J. Gui, J. Am. Chem. Soc. 2020, $142,5007-5012$.

[3] a) M. Yan, J. C. Lo, J. T. Edwards, P. S. Baran, J. Am. Chem. Soc. 2016, 138, $12692-12714$; b) J. M. Smith, S. J. Harwood, P. S. Baran, Acc. Chem. Res. 2018, 51, 1807-1817; c) K. J. Romero, M. S. Galliher, D. A. Pratt, C. R. J. Stephenson, Chem. Soc. Rev. 2018, 47, 7851-7866.

[4] a) F. L. Duecker, F. Reuß, P. Heretsch, Org. Biomol. Chem. 2019, 17, $1624-$ 1633; b) F. Noack, R. C. Heinze, P. Heretsch, Synthesis 2019, 51, $2039-$ 2057.

[5] R. A. Shenvi, C. A. Guerrero, J. Shi, C.-C. Li, P. S. Baran, J. Am. Chem. Soc. 2008, 130, $7241-7243$.

[6] Z. Lu, X. Zhang, Z. Guo, Y. Chen, T. Mu, A. Li, J. Am. Chem. Soc. 2018, $140,9211-9218$.

[7] R. C. Heinze, D. Lentz, P. Heretsch, Angew. Chem. Int. Ed. 2016, 55, 11656-11659; Angew. Chem. 2016, 128, 11828-11831.

[8] R. C. Heinze, P. Heretsch, J. Am. Chem. Soc. 2019, 141, 1222-1226.

[9] F. L. Duecker, R. C. Heinze, M. Mueller, S. Zhang, P. Heretsch, Org. Lett. 2020, 22, 1585-1588.

[10] a) T. Amagata, M. Doi, M. Tohgo, K. Minoura, A. Numata, Chem. Commun. 1999, 1321-1322; b) T. Amagata, M. Tanaka, T. Yamada, M. Doi, K. Minoura, H. Ohishi, T. Yamori, A. Numata, J. Nat. Prod. 2007, 70, $1731-1740$.

[11] a) J. Gong, P. Sun, N. Jiang, R. Riccio, G. Lauro, G. Bifulco, T.-J. Li, W. H. Gerwick, W. Zhang, Org. Lett. 2014, 16, 2224-2227; b) J. Li, H. Tang, T. Kurtán, A. Mándi, C.-L. Zhuang, L. Su, G.-L. Zheng, W. Zhang, J. Nat. Prod. 2018, 81, 1645-1650.

[12] W. Gao, C. Chai, Y. He, F. Li, X. Hao, F. Cao, L. Gu, J. Liu, Z. Hu, Y. Zhang, Org. Lett. 2019, 21, 8469-8472.

[13] F. L. Duecker, R. C. Heinze, P. Heretsch, J. Am. Chem. Soc. 2020, 142, 104- 108 .

[14] a) L. Canonica, B. Danieli, G. Lesma, G. Palmisano, J. Chem. Soc. Chem. Commun. 1985, 1321-1322; b) L. Canonica, B. Danieli, G. Lesma, G. Palmisano, A. Mugnoli, Helv. Chim. Acta 1987, 70, 701-716.

[15] a) P. Dowd, S.-C. Choi, J. Am. Chem. Soc. 1987, 109, 6548-6549; b) A. L. J. Beckwith, D. M. O'Shea, S. Gerba, S. W. Westwood, J. Chem. Soc., Chem. Commun. 1987, 666-667; c) A. L. J. Beckwith, D. M. O'Shea, S. W. Westwood, J. Am. Chem. Soc. 1988, 110, 2565-2575; d) P. Dowd, W. Zhang, Chem. Rev. 1993, 93, $2091-2115$.

[16] a) A. Burawoy, J. Chem. Soc. 1937, 409-411; b) D. H. R. Barton, C. H. Robinson, J. Chem. Soc. 1954, 3045-3051; c) E. V. Yablonskaya, G. M. Segal, Chem. Nat. Compd. 1971, 7, 476-480; d) C. Brosa, R. Puig, X. Comas, C. Fernández, Steroids 1996, 61, 540-543.

[17] D. H. R. Barton, P. G. Feakins, J. P. Poyser, P. G. Sammes, J. Chem. Soc. (C) Org. 1970, 1584-1591.

[18] a) C. Meystre, K. Heusler, J. Kalvoda, P. Wieland, G. Anner, A. Wettstein, Helv. Chim. Acta 1962, 45, 1317-1343; b) V. A. Khripach, V. N. Zhabinskii, G. P. Fando, N. B. Khripach, B. Schneider, Arkivoc 2008, ix, 20-28.

[19] a) J. S. Guo, X. T. Liang, Chin. Chem. Lett. 1991, 2, 189-190; b) F. Noack, B. Hartmayer, P. Heretsch, Synthesis 2018, 50, 809-820.

[20] a) R. A. Sneen, N. P. Matheny, J. Am. Chem. Soc. 1964, 86, 3905-3906; b) M. Ottolenghi, K. Bar-Eli, H. Linschitz, J. Am. Chem. Soc. 1965, 87, 1809 ; c) M. L. Mihailović, Ž. Čeković, J. Stanković, J. Chem. Soc. 1969, $981-982$.

[21] Y. Wang, W. Ju, H. Tian, S. Sun, X. Li, W. Tian, J. Gui, J. Am. Chem. Soc. 2019, 141, $5021-5033$.

[22] K. Zhao, K. Yamashita, J. E. Carpenter, T. C. Sherwood, W. R. Ewing, P. T. W. Cheng, R. R. Knowles, J. Am. Chem. Soc. 2019, 141, 8752-8757.

[23] H. Hosoda, K. Yamashita, N. Chino, T. Nambara, Chem. Pharm. Bull. 1976, 24, 1860-1864

[24] a) W. R. Nes, E. Mosettig, J. Am. Chem. Soc. 1954, 76, 3182-3186; b) N. Bosworth, A. Emke, J. M. Midgley, C. J. Moore, W. B. Whalley, G. Ferguson, W. C. Marsh, J. Chem. Soc. Perkin Trans. 1 1977, 805-809; c) W. R. Nes, J. A. Steele, E. Mosettig, J. Am. Chem. Soc. 1958, 80, 5230-5232; d) T. Nakada, S. Yamamura, Tetrahedron 2000, 56, 2595-2602; e) H. 
Koshino, T. Yoshihara, S. Sakamura, T. Shimanuki, T. Sato, A. Tajimi, Phytochemistry 1989, 28, 771-772; f) S. Kosemura, S. Uotsu, S. Yamamura, Tetrahedron Lett. 1995, 36, 7481-7482; g) X. Luo, F. Li, P. B. Shinde, J. Hong, C.-O. Lee, K. S. Im, J. H. Jung, J. Nat. Prod. 2006, 69, 1760-1768.

[25] a) G. Stork, J. d'Angelo, J. Am. Chem. Soc. 1974, 96, 7114-7116; b) J. E. McMurry, A. Andrus, G. M. Ksander, J. H. Musser, M. A. Johnson, J. Am. Chem. Soc. 1979, 101, 1330-1332.

[26] a) R. H. Mueller, J. G. Gillick, J. Org. Chem. 1978, 43, 4647-4648; b) M. J. Taschner, A. Shahripour, J. Am. Chem. Soc. 1985, 107, 5570-5572; c) The benefits of this approach are the possibility to easily accomplish stoichiometric reductions as well as circumventing the sometimes tedious removal of ammonia from the reaction mixture.

[27] a) S. Kobayashi, I. Hachiya, H. Ishitani, M. Araki, Synlett 1993, 472-474; b) A. B. Smith III, L. Kürti, A. H. Davulcu, Y. S. Cho, Org. Process Res. Dev. 2007, 11, 19-24; c) K. Fukaya, Y. Tanaka, A. Y. Sato, K. Kodama, H. Yamazaki, T. Ishimoto, Y. Nozaki, Y. M. Iwaki, Y. Yuki, K. Umei, T. Sugai, Y. Yamaguchi, A. Watanabe, T. Oishi, T. Sato, N. Chida, Org. Lett. 2015, 17, 2570 2573.

[28] K. Fujioka, N. Miyamoto, H. Toya, K. Okano, H. Tokuyama, Synlett 2016, $27,621-625$.

[29] N. Ozasa, M. Wadamoto, K. Ishihara, H. Yamamoto, Synlett 2003, 3, $2219-2221$

[30] a) B. M. Trost, H. Hiemstra, Tetrahedron 1986, 42, 3323-3332; b) M. R. Tremblay, A. Lescarbeau, M. J. Grogan, E. Tan, G. Lin, B. C. Austad, L.-C. Yu, M. L. Behnke, S. J. Nair, M. Hagel, K. White, J. Colney, J. D. Manna, T. M. Alvarez-Diez, J. Hoyt, C. N. Woodward, J. R. Sydor, M. Pink, J. MacDougall, M. J. Campbell, J. Cushing, J. Ferguson, M. S. Curtis, K. McGovern, M. A. Read, V. J. Palombella, J. Adams, A. C. Castro, J. Med. Chem. 2009, 52, 4400-4418.

[31] a) F. H. Bottom, F. J. McQuillin, Tetrahedron Lett. 1968, 9, 459-462; b) T. Kaneko, H. Wong, Tetrahedron Lett. 1987, 28, 517-520; c) D. V. Patel,
R. J. Schmidt, E. M. Gordon, J. Org. Chem. 1992, 57, 7143-7151; d) H. Nakamura, K. Ishihara, H. Yamamoto, J. Org. Chem. 2002, 67, 51245137.

[32] a) J. Schreiber, H. Maag, N. Hashimoto, A. Eschenmoser, Angew. Chem. Int. Ed. Engl. 1971, 10, 330-331; Angew. Chem. 1971, 83, 355-357; b) S. Danishefsky, T. Kitahara, R. McKee, P. F. Schuda, J. Am. Chem. Soc. 1976, 98, 6715-6717.

[33] a) H. Nishiyama, T. Kitajima, M. Matsumoto, K. Itoh, J. Chem. Soc. 1984, 49, 2298-2300; b) G. Stork, M. Kahn, J. Am. Chem. Soc. 1985, 107, 500501.

[34] K. Tamao, N. Ishida, M. Kumada, J. Org. Chem. 1983, 48, 2120-2122.

[35] a) M. Sawamura, Y. Kawaguchi, E. Nakamura, Synlett 1997, 1997, 801 802 ;b) E. J. Corey, J. W. Suggs, J. Org. Chem. 1975, 40, 2554-2555.

[36] M. L. Landry, G. M. McKenna, N. Z. Burns, J. Am. Chem. Soc. 2019, 141, $2867-2871$.

[37] D. Zhu, B. Yu, J. Am. Chem. Soc. 2015, 137, 15098-15101.

[38] a) W. C. Dow, T. Gebreysus, S. Popov, R. M. K. Carlson, C. Djerassi, Steroids 1983, 42, 217-230; b) V. A. Khripach, V. N. Zhabinskii, O. V. Konstantinova, N. B. Khripach, A.P. Antonchick, B. Schneider, Steroids 2002, 67, 597-603; c) F. O. McCarthy, J. Chopra, A. Ford, S. A. Hogan, J. P. Kerry, N. M. O'Brien, E. Ryan, A. R. Maguire, Org. Biomol. Chem. 2005, 3, 30593065.

[39] C. Obradors, R. M. Martinez, R. A. Shenvi, J. Am. Chem. Soc. 2016, 138, $4962-4971$.

Manuscript received: March 21, 2020

Revised manuscript received: April 17, 2020

Accepted manuscript online: April 21, 2020

Version of record online: June 18, 2020 